US Army Corps

of Engineers ${ }_{\circledast}$

Engineer Research and

Development Center

\title{
Modeling Relevant to Safe Operations of Naval Vessels in Arctic Conditions
}

Numerical Modeling of Ice Loads

Arnold Song, Matthew Parno, Brendan West,

September 2018

and Devin O'Connor

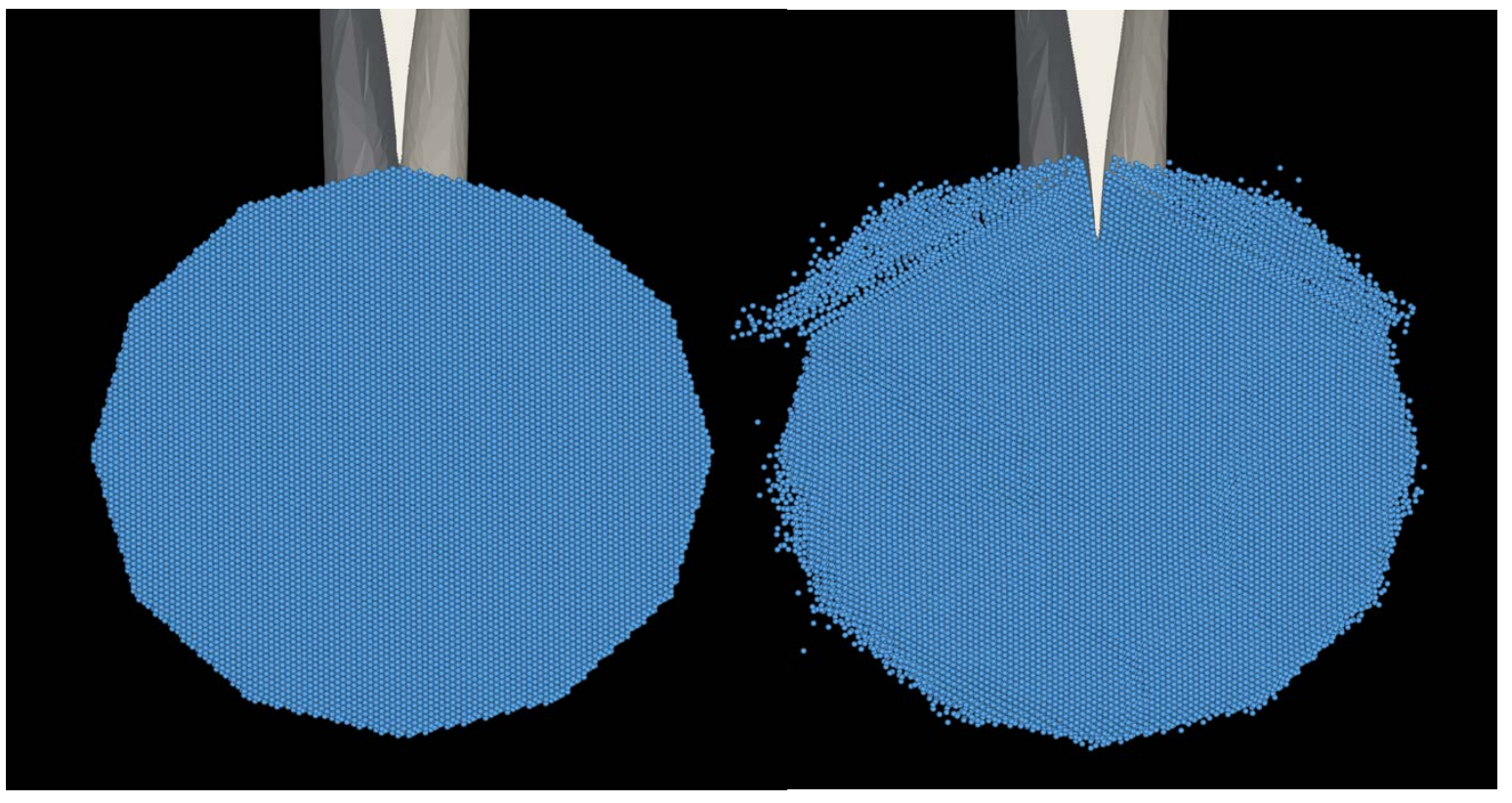


The U.S. Army Engineer Research and Development Center (ERDC) solves the nation's toughest engineering and environmental challenges. ERDC develops innovative solutions in civil and military engineering, geospatial sciences, water resources, and environmental sciences for the Army, the Department of Defense, civilian agencies, and our nation's public good. Find out more at www.erdc.usace.army.mil.

To search for other technical reports published by ERDC, visit the ERDC online library at http://acwc.sdp.sirsi.net/client/default. 


\section{Modeling Relevant to Safe Operations of Naval Vessels in Arctic Conditions}

Numerical Modeling of Ice Loads

Arnold Song, Matthew Parno, Brendan West, and Devin O'Connor

Cold Regions Research and Engineering Laboratory

U.S. Army Engineer Research and Development Center

72 Lyme Road

Hanover, NH 03755

Final report

Approved for public release; distribution is unlimited.

Prepared for Office of Naval Research

One Liberty Center

875 N. Randolph Street, Suite 1425

Arlington, VA 22203-1995

Under Military Interdepartmental Purchase Request (MIPR) N0001415MP00317, "Modeling relevant to safe operations of US Navy vessels in Arctic conditions." 


\section{Abstract}

The Arctic is undergoing profound and rapid change. Diminishing ice in the Arctic will lead to significant changes in the region's activity level as sea routes begin to open and ice conditions become less restrictive. The U.S. Navy may be asked to operate in waters with up to $40 \%$ ice cover.

This work addresses Navy Arctic Roadmap action items to understand the capability, limitations, and operational considerations for successful and safe operation of naval surface vessels in the presence of ice. Current ice impact models were developed for impact scenarios and hull forms more appropriate for Polar Class ships rather than naval hull forms.

The primary unknowns needed to assess operational risks are the magnitude of the pressures that a surface vessel may experience in the case of an ice impact and the structural response to those impact pressures. For this work, we are solely interested in estimating the location and pressures of ice impacts on combatant hull forms. We present an alternative approach that uses the DEM approach to modeling the ice impact problem.

DISCLAIMER: The contents of this report are not to be used for advertising, publication, or promotional purposes. Citation of trade names does not constitute an official endorsement or approval of the use of such commercial products. All product names and trademarks cited are the property of their respective owners. The findings of this report are not to be construed as an official Department of the Army position unless so designated by other authorized documents. 


\section{Contents}

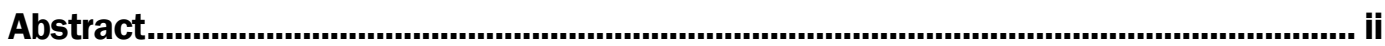

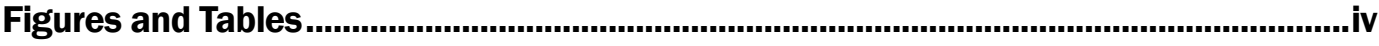

Preface

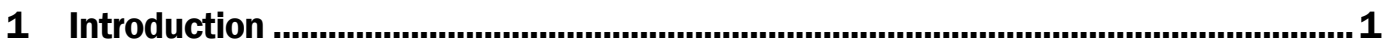

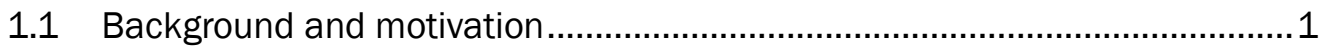

1.2 U.S. Navy Artic roadmap..........................................................................

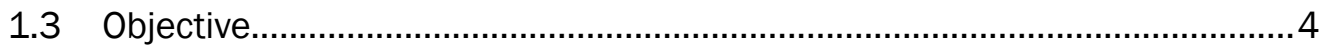

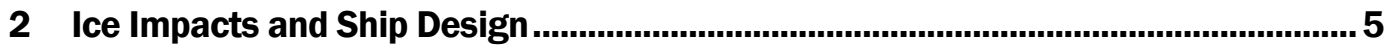

2.1 Classification rules and design guidance ............................................... 5

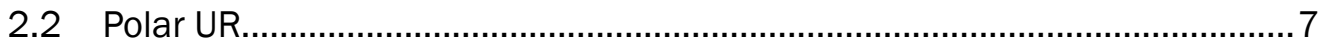

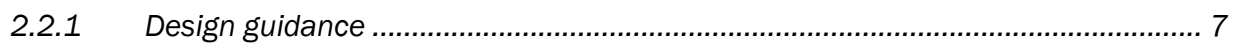

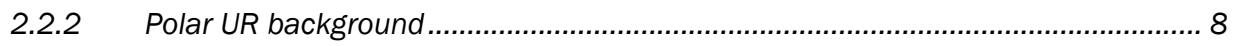

2.3 Limitations of the Polar UR ice model for Navy ships.................................... 9

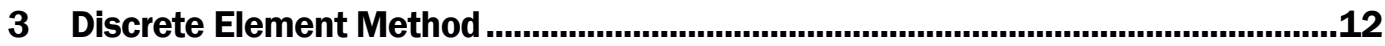

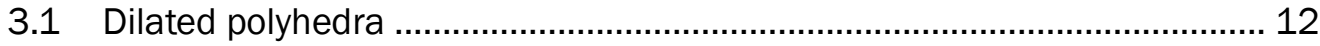

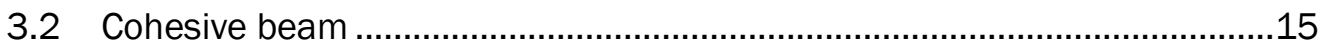

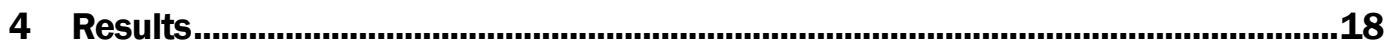

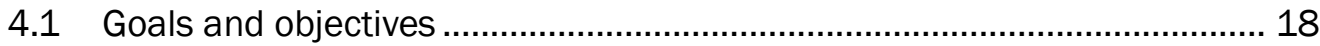

4.2 Ice impact loads comparison between icebreaking and combatant

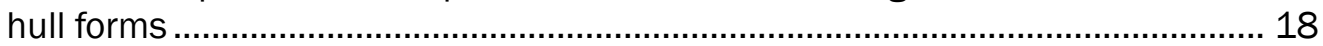

4.2.1 Ice floe geometry and properties ................................................................... 19

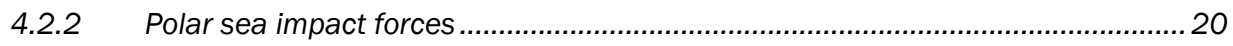

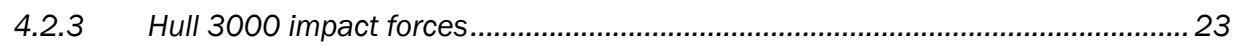

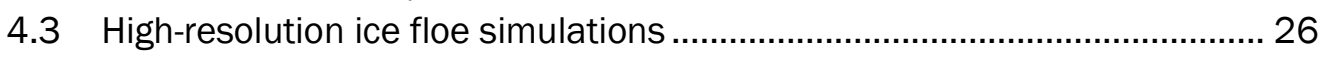

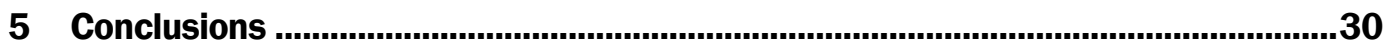

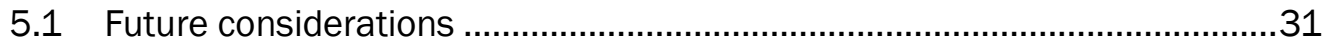

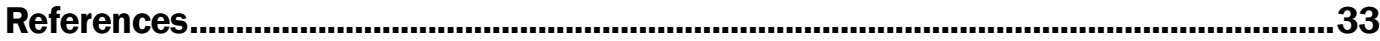

Report Documentation Page 


\section{Figures and Tables}

\section{Figures}

Figure 1. The current sea ice extent record and model projections. The Arctic sea ice extent declined more than $60 \%$ during the satellite era (1979-present). The colored lines and shaded regions represent the sea ice extent predictions and variances for several Representative Concentration Pathways (RCP). RCP 8.5 represents a scenario with high greenhouse gas emissions and predicts an essentially ice free Arctic by 2060 . Note that ice extents predicted under the RCP 8.5 scenario under predicts extent compared to observations for recent years (Melillo et al. 2014).

Figure 2. The predicted availability of Arctic transit routes from years 2012 through 2030 (Navy Task Force Climate Change 2014).

Figure 3. Classes of Polar ships. The Polar Class (PC) requirements are developed by the IACS and the Baltic, or Finnish-Swedish, Class requirements are developed by the Finnish and Swedish maritime authorities (after Reid et al. 2014).

Figure 4. Speed limitations for level ice by ice class using POLARIS (after Canada et al. 2014).

Figure 5. Illustration of the dilated polyhedron and the contact condition. A dilated polyhedron is constructed using a polyhedron as the base geometry and extending the surface normally by a distance specified by the dilation radius, as shown in (a). When the base geometries of two bodies are less than the dilation radius, the bodies are said to be in contact, as shown in (b). The interaction forces between the two bodies is a function of the penetration depth.

Figure 6. Two discrete element particles with a cohesive beam (blue) connecting their centroids. The local particle coordinate systems are shown in red while the beam coordinate system is shown in green. The angle vectors $\theta 1$ and $\theta 2$ are used to calculate beam bending and torsion.

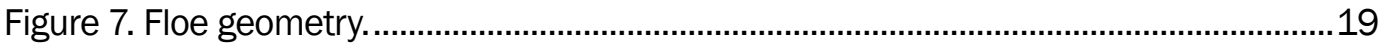

Figure 8. Impact location map on the Polar Sea.............................................................21

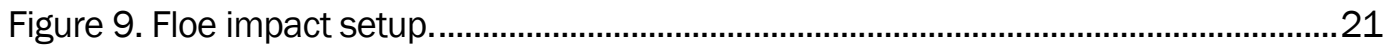

Figure 10. Impact force time trace for Polar Sea at $10.0 \mathrm{~m}$ from bow................................22

Figure 11. Polar Sea ice impact forces as a function of distance from the bow.................23

Figure 12. Impact location map on the Hull3000................................................................. 24

Figure 13. Detail of bulbous bow region. The region of concavity, which is indicated by a sharp transition of surface normal direction (i.e., red to blue), above the bow bulb will lead to multiple contact points between the ship and the hull. This is illustrated by a vertical line dropped from the specified impact location that has multiple intersection points.

Figure 14. Impact force time trace for Hull3000 at $10.0 \mathrm{~m}$ from bow..............................25

Figure 15. Hull3000 impact forces as a function of impact location....................................26

Figure 16. Detail of high-resolution multiparticle ice floe. ..............................................2

Figure 17. Illustration of the impact configurations for high-resolution simulations. .........27 
Figure 18. Comparison of impact forces between direct and glancing blows near

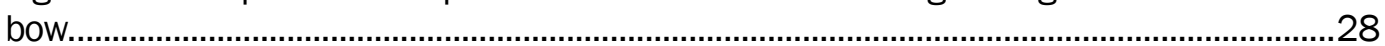

Figure 19. Detail images of stem-on impact with multiparticle floe.....................................29

\section{Tables}

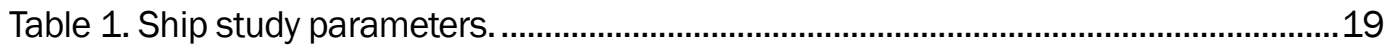

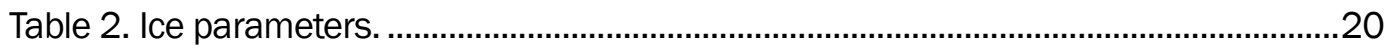

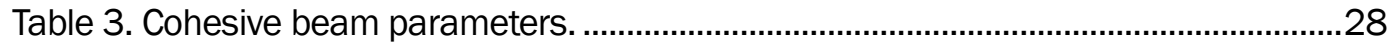




\section{Preface}

This study was conducted for the Office of Naval Research under Military Interdepartmental Purchase Request (MIPR) Noo01415MPoo317, "Modeling relevant to safe operations of U.S. Navy vessels in Arctic conditions." The program manager was Dr. Paul Hess in Code 331, Structural Reliability and Seabasing Technologies.

The work was performed by the Terrestrial and Cryospheric Sciences Branch (CEERD-RRG) of the Research and Engineering Division (CEERD-RR), U.S. Army Engineer Research and Development Center, Cold Regions Research and Engineering Laboratory (ERDC-CRREL). At the time of publication, Dr. John Weatherly was Chief, CEERD-RRG; Mr. J. D. Horne was Chief, CEERD-RR; and Dr. Mark Moran was the Technical Director, CEERD-RZT. The Deputy Director of ERDC-CRREL was Mr. David B. Ringleberg, and the Director was Dr. Joseph L. Corriveau.

The Commander of ERDC was COL Ivan P. Beckman, and the Director was Dr. David W. Pittman. 


\section{Introduction}

\subsection{Background and motivation}

This report is a companion to a previous report entitled, "Modeling Relevant to Safe Operations of U.S. Navy Vessels in Arctic Conditions: Physical Modeling of Ice Loads" [1]. Accordingly, the motivation and background sections are shared by both reports.

The conditions in the Arctic are undergoing profound and rapid change with the summer ice extent exhibiting a steady decline. The summer minimum has decreased from approximately 7.5 million $\mathrm{km}^{2}$ in 1979 to 3 million $\mathrm{km}^{2}$ in recent years [2] as shown in Figure 1.

Figure 1. The current sea ice extent record and model projections. The Arctic sea ice extent declined more than $60 \%$ during the satellite era (1979-present). The colored lines and shaded regions represent the sea ice extent predictions and variances for several Representative Concentration Pathways (RCP). RCP 8.5 represents a scenario with high greenhouse gas emissions and predicts an essentially ice free Arctic by 2060. Note that ice extents predicted under the RCP 8.5 scenario under predicts extent compared to observations for recent years (Melillo et al. 2014).

\section{Projected Arctic Sea Ice Decline}

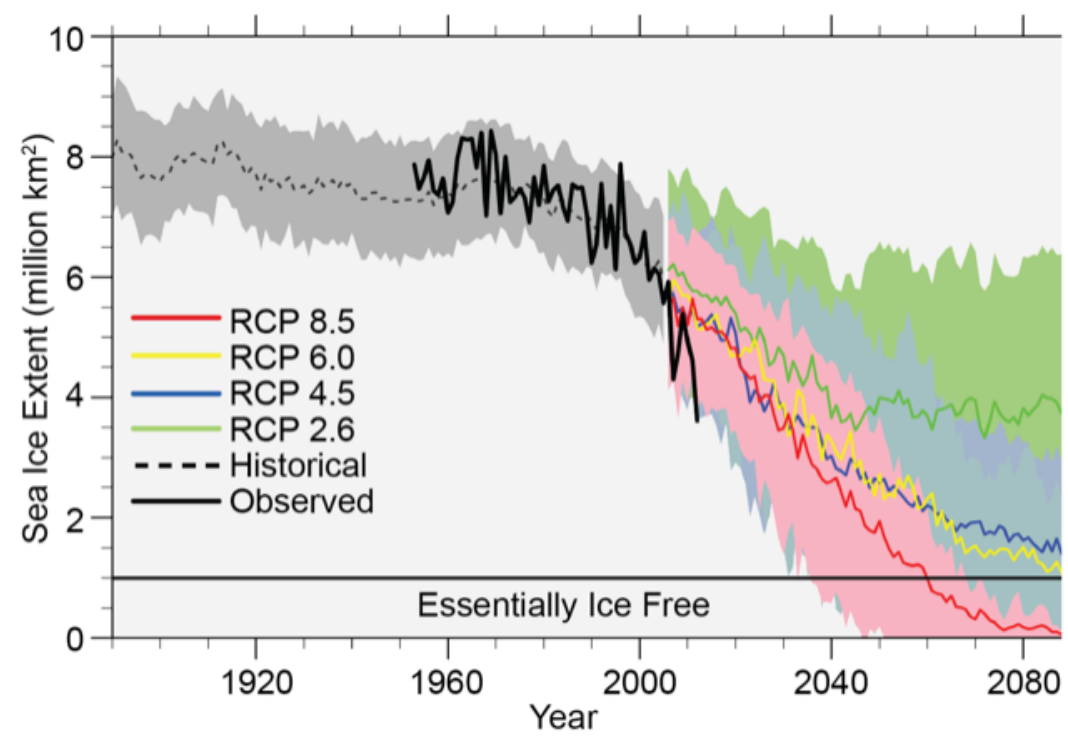

This trend is expected to accelerate as the sea ice cover diminishes further because of the dramatic difference between the albedo (i.e., surface reflectivity) of ice (0.5 to 0.7) and open water (0.10). As the ice melts and 
is replaced by "dark" water, more incoming radiation is absorbed by the water rather than reflected by ice and snow cover. This leads to a positive feedback loop where the added radiative heat flux into the ocean results in thinner (and "darker") ice resulting in even more increase in the radiative heat flux $[3,4,5]$. The result of this warming amplification is a severe acceleration in the decline of Arctic ice cover. The Intergovernmental Panel on Climate Change (IPCC) projects that a nearly ice-free summer in the Arctic is likely to occur before mid-century [6].

Ice-free seasons will lead to significant changes in the activity level in the Arctic in the next 20 to 25 years as sea routes begin to open and ice conditions become less forbidding. The Office of Naval Intelligence projects over the next 5-10 years (through 2020-2025) that Bering Strait traffic will increase more than $100 \%$ and that the number of vessels traversing the Northern Sea Route, which tracks primarily along Russia's northern coast, will increase more than tenfold (Figure 2). A large proportion of this seasonal ice loss is projected to occur in the Chukchi and Beaufort Seas where the United States has sovereign interest and search and rescue obligations. The diminished ice cover will encourage an increase in ship traffic in the Beaufort and Chukchi Seas, coming mostly in the forms of ecotourism and energy extraction activities. A search and rescue response for either type of activity will test the capability of the U.S. Coast Guard (USCG) and may require the assistance of the U.S. Navy, in some instances.

Figure 2. The predicted availability of Arctic transit routes from years 2012 through 2030 (Navy Task Force Climate Change 2014).
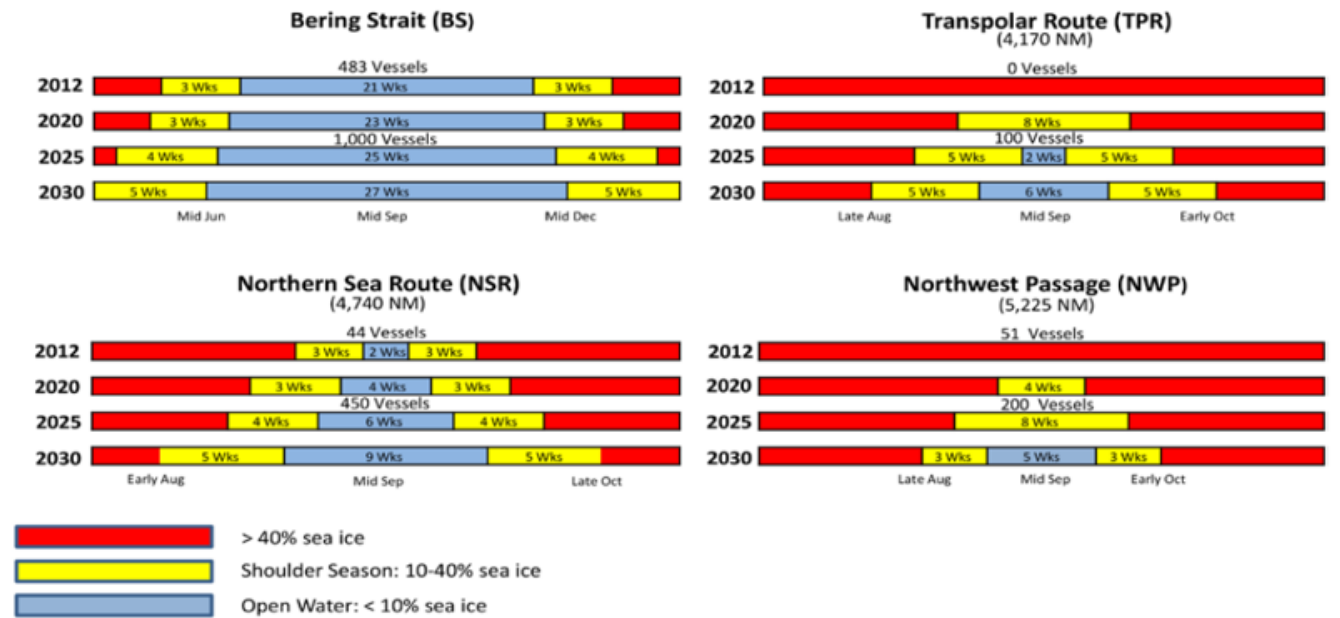

$>40 \%$ sea ice

Shoulder Season: $10-40 \%$ sea ice

Open Water: $<10 \%$ sea ice 
Given the increased extent and duration of open water in the Arctic Ocean, there is a high probability that the Navy will need to operate in waters with partial ice cover ranging from $10 \%$ to $40 \%$. This likelihood raises important questions: How well can existing Navy ships withstand intentional or accidental ice impacts? What are their safe speeds limits?

Accordingly, a tool is needed to accurately estimate ice-ship impact loads to assess the risk to current naval vessels and to develop guidance for oper ation in ice covered waters.

\subsection{U.S. Navy Artic roadmap}

This work addresses U.S. Navy Arctic Roadmap [7] specific action items (identified with the corresponding Roadmap numbers in the parentheses) to understand the capability, limitations, and operational considerations for successful operation of U.S. Navy surface vessels in the presence of ice, namely the following items:

(2.1.10) Develop Arctic CONOPs [concepts of operation] for naval platforms and update as new capabilities are developed.

(2.2.5) Provide S\&T [science and technology] plans for Arctic assessment and prediction to include:

- Impact of Arctic environment on naval systems

- Development of new technologies and adoption of existing technologies (e.g., sensors, platforms, and communications) for sustained operation and observation in the Arctic

(2.7.2) Identify current capabilities of existing platforms to operate in open water ( $<10 \%$ sea ice) and shoulder seasons ( $<40 \%$ sea ice)

(2.7.3) Identify future platforms and their engineering requirements that will operate in open water ( $<10 \%$ sea ice) and shoulder seasons $(<40 \%$ sea ice) by mid $2020 \mathrm{~s}$

(2.7.8) Evaluate requirements for sustainment of forces operating in the Arctic 
(2.7.10) Evaluate requirements for expeditionary units to conduct operations in the Arctic. Environments include on ice, ashore, on permafrost, under ice diving, littoral operations and construction including underwater construction in freezing/subzero conditions.

\subsection{Objective}

Pursuant to these action items, the primary unknowns needed to assess operational risks are the magnitude of the pressures that a surface vessel may experience in the case of an ice impact and the structural response to those impact pressures. For this work, we are solely interested in estimating the location and load magnitudes of ice impacts on naval hull forms. 


\section{Ice Impacts and Ship Design}

The design of ships that intend to operate in ice-covered waters is prominently driven to withstand potential ice-impact forces. These ships range from Polar Class icebreakers, whose roles include breaking channels through intact ice sheets and ice ridges, to ice-strengthened cargo ships and tankers, which generally operate in marginal ice, thin intact ice, or pre-broken channels. A major design goal for ice-capable ships is to minimize ice forces or to optimize hull strength for the ice thicknesses and strengths expected in normal operating conditions. Typical rounded, spoon-shaped bow forms promote breaking of ice sheets and large floes in their weaker flexural mode, which enables safe and capable operation in ice-covered waters; however, these designs necessarily trade off openwater performance to maximize ice-capable performance.

In contrast, naval surface ships are designed to maximize their military capabilities, which include open-water speed, maneuverability, and seakeeping. In contrast to ice-capable ships, naval hull forms have fine bow shapes with near-vertical sides and slender, lightweight hulls. Because of the near vertical hull angles for naval hull forms, the peak loads on the hull will likely be controlled by ice crushing and momentum exchange rather than the flexural failure mode promoted by ice-capable hull forms.

\subsection{Classification rules and design guidance}

Ship classification societies, such as ABS and Lloyd's Register, have collaboratively developed design rules and guidance to evaluate ship structural integrity and to provide guidance on safe operation, mainly for actuarial purposes. Since the early 1990s, these organizations have also helped standardize the classification of ice-capable ships.

The International Association of Classification Societies (IACS) has produced the Unified Requirements for Polar Ships (Polar UR) operating in ice-covered waters [8]. The seven IACS Polar ice classes in this requirements document are defined using a range of hull-strength factors that determine a ship's ability to withstand ice forces for ice conditions related to categories in the World Metrological Organization's (WMO) sea ice nomenclature (Figure 3). The Polar UR includes formulas to estimate ice forces and the resulting structural response of the hull design used to 
determine the ability of that design to endure each Class's limiting ice condition.

Figure 3. Classes of Polar ships. The Polar Class (PC) requirements are developed by the IACS and the Baltic, or Finnish-Swedish, Class requirements are developed by the Finnish and Swedish maritime authorities (after Reid et al. 2014).

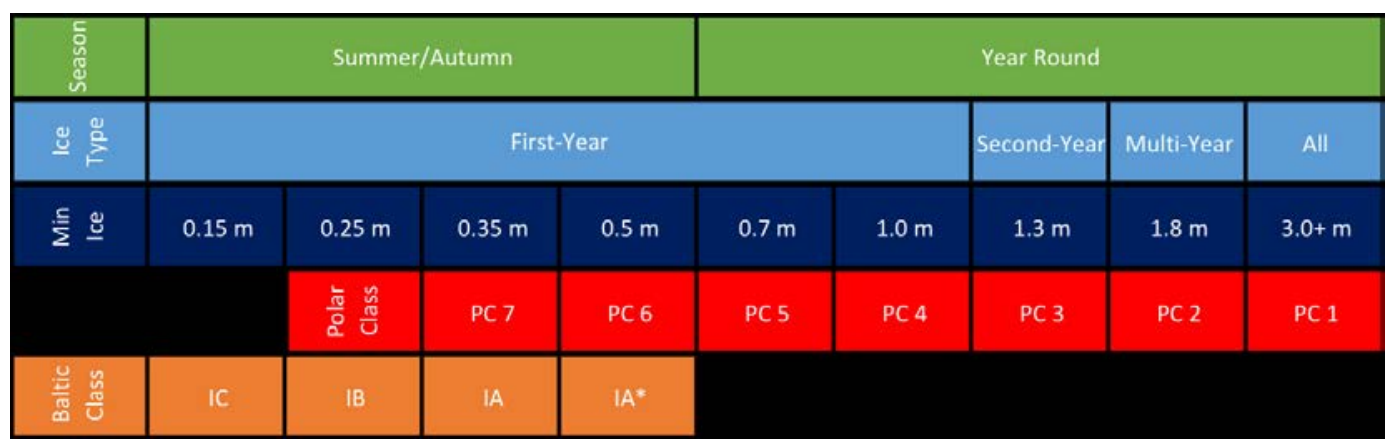

The primary concern of the Polar UR is the hull form design and strength required to operate in specific ice conditions, but it does not provide guidance for safe operations in these conditions (i.e., safe speeds or approach angles). To address this gap in operational guidance for icecovered conditions, the International Maritime Organization (IMO) has developed a Polar Operational Limit Assessment Risk Indexing System (POLARIS) that introduced a three-option decision guidance (go, slowspeed, no-go) for ship operators. As shown in Figure 4, this guidance is based on vessel speed, ice concentration, and ship classification. The POLARIS guidance derives largely from operational experience with ships in ice rather than the physical details of ice-ship interactions. Better understanding of ice-impact forces, over a range of hull forms and ice conditions, could therefore lead to significant improvements in operational guidance. 
Figure 4. Speed limitations for level ice by ice class using POLARIS (after Canada et al. 2014).

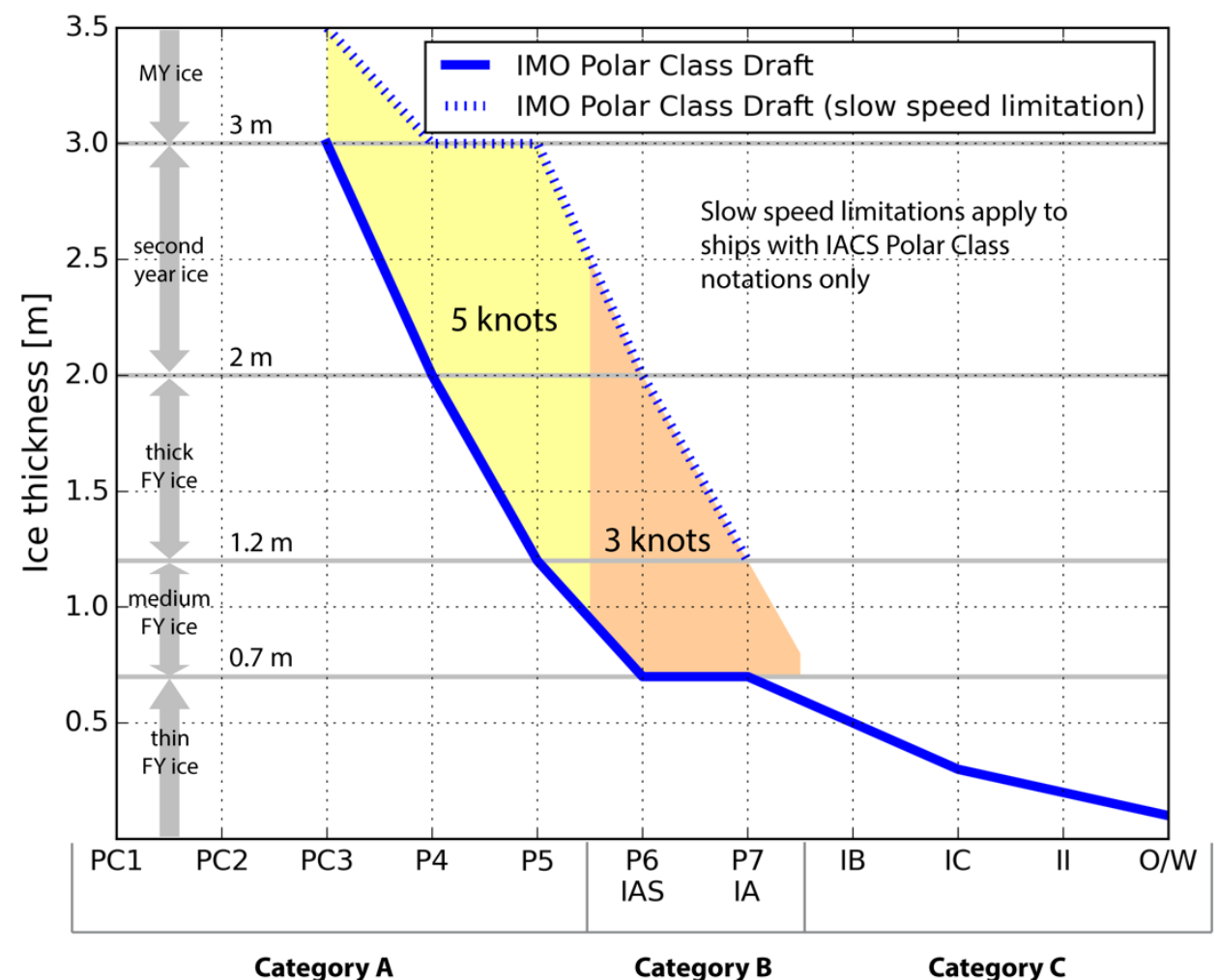

\subsection{Polar UR}

\subsubsection{Design guidance}

The Polar UR specifically warns against broad application of its design guidance: "Design ice forces calculated according to [Section] I2.3.2 [in the IACS Polar Class requirements] are only valid for vessels with icebreaking forms. Design ice forces for any other bow forms are to be specially considered by the member society." This partly stems from the fact that icebreaking hull forms are designed to encourage the flexural failure of the ice by producing a downward loading action, which is not the case for the near vertical surfaces on naval hull forms. The Polar UR guidance also focuses on a glancing impact near the bow to determine the ship structure required to resist ice load, which may not be the case in practice. The design ice load is assumed to be well characterized by an average pressure uniformly distributed over a rectangular load patch. These assumptions may be appropriate for a classification system based on worst-case load conditions on icebreaking hull forms but may not provide sufficient accuracy to develop safe-speeds guidance in the case of naval hull forms. 


\subsubsection{Polar UR background}

This section summarizes the technical approach underpinning the Polar UR, which is a combination of Popov collision mechanics [9] that uses empirically measured ice pressure-area relationships. This approach is fully detailed in Dolny et al. [10], which includes an ice-load model and a ship structural response model. This report focuses solely on the ice-load model and its relevance to naval vessels operating in ice-covered waters. In the Polar UR case, ice-impact forces are calculated for a glancing impact between a ship's bow and an ice floe of uniform thickness. The impact forces arise from momentum exchange between the ship and the ice floe through two modes of ice failure: (1) crushing or compressive failure, which dominates at low speeds, in thick ice, and for steeply angled hull forms (e.g., combatants), and (2) flexural failure, which dominates at high speeds, in thin ice, and in impacts with shallowly angled hull forms (e.g., ice-breakers). The impact load calculations detailed below are based on a crushing-only mode of failure. Flexural failure is assumed to be catastrophic and therefore caps the calculated crushing-only impact loads.

The mechanics are based on the Popov collision model [9] but are modified to include a wedge-shaped ice edge and a pressure-area ice indentation model. The ice-ship impact force is calculated by equating the normal kinetic energy to the ice crushing energy. The crushing energy is found by integrating the normal force over the penetration depth, as follows:

$$
\frac{1}{2} M_{e} V_{n}^{2}=\int_{0}^{\delta_{\max }} F_{n}(\delta) d \delta
$$

where

$$
\begin{aligned}
& M_{e}=\text { the effective mass of the ice-ship configuration, } \\
& V_{n}=\text { the relative normal velocity at the impact location, } \\
& \delta=\text { the penetration depth, } \\
& \delta_{\max }=\text { the maximum penetration depth, and } \\
& F_{n}=\text { the hull-normal impact force at the impact location. }
\end{aligned}
$$

As interaction speed (kinetic energy) increases from zero, the design ice load follows the crushing mode calculation until the flexural-mode limit is reached. Because the flexural-failure stress is assumed to be independent 
of strain rate and hydrodynamic effects, the flexural limit in the Polar UR is independent of ship speed. Daley and Liu [11] proposed an extension to the flexural mode to account for hydrodynamic effects via a Froude number correction, which introduces a slight increase in failure load with increasing speed.

The normal impact force resulting from the crushing failure of ice is determined using an empirical pressure-area relationship of the form

$$
F_{n}(\delta)=P(\delta) A(\delta)
$$

where the contact area is denoted as $A$ and the contact pressure, $P$, is determined using an area-dependent power law, such that

$$
P(\delta)=P_{0} A(\delta)^{\gamma}
$$

where $P_{o}$ and $\gamma$ are fitting parameters.

Equation 2 links the average ice pressure and the ice-hull contact area. The justification for such a relationship has been the subject of numerous investigations for both ships (e.g., 12, 13, 14) and offshore structures (e.g., $15,16)$. In general, average ice interaction pressures decrease as contact area increases during an impact with respect to the so-called "spatial" or "local" pressure-area relationship. Theories have not satisfactorily established the appropriate form of the pressure-area relationship and its link to ice-failure processes. In addition, the loading function (or pressurearea relationship) is an empirical correlation to field and physical-model data highlighted by the dimensional inconsistency of Equation 3, which limits the generality of these relationships. The Polar UR assumes that $\gamma=$ -0.1 and that $P_{o}$ varies with Polar Class to reflect the ice-strength characteristic of the particular class's requirements.

\subsection{Limitations of the Polar UR ice model for Navy ships}

The assumptions and simplifications in the Polar UR ice model are supported by decades of operational experience with Polar Class ships in ice, and the empirical coefficients derive from extensive full-scale data. Because of the significant differences between icebreaking and naval vessel hull forms, especially in the bow region, while satisfactory for Polar Class hull forms, this impact model may not accurately represent ice-interaction 
mechanics relevant to the hull forms of naval ships operating in marginal ice cover. The following paragraphs summarize some key limitations of the Polar UR ice model and current research on ship-ice interactions as they pertain to Navy hull forms.

Ice rebound and impact forces. As described previously, Popov collision mechanics assume that ice crushing dissipates all of the effective kinetic energy of the impact. For ice-capable ships striking large floes or intact ice sheets, ice rebound may be small; thus, its omission introduces only minor conservatism. However, for Navy ships striking relatively small, isolated floes, ice rebound could be important, therefore, the impact forces using Popov collision mechanics may be overly conservative (i.e., unrealistically large).

Inertial hydrodynamic effects. Because it anticipates collisions with large or intact ice sheets, the Polar UR ice model devotes little attention to inertial hydrodynamics effects (e.g., added mass). These effects are likely to be important for impacts with discrete ice floes at low concentrations. Added mass could vary substantially with floe size, shape, and lateral confinement for discrete ice floes.

Failure mode effects and equipment damage. The waterline bow forms of ice-capable ships are broad and rounded, and they provide shallow entry angles along the vertical centerline to promote downward ice breaking. The Polar UR thus anticipates glancing impacts near the bow. Naval vessels, having fine, steep-sided bows, are likely to impact some ice floes stem-on. This could be beneficial: the stem is a strong structural location; splitting the ice floe would reduce forces relative to pure crushing, and rotational energy imparted from eccentric stem-on impacts would reduce ice-interaction energy. However, some ships have bow-mounted appendages that could be vulnerable to impact by under-turned ice pieces. Also, maneuvering to avoid stem-on impacts raises issues of safe ship handling in varying ice concentrations. These issues are simply not addressed in the Polar UR or in the research that underpins it.

Applicable pressure-area relationship. For ice crushing, the Polar UR uses a simple pressure-area relationship based on data from ice-capable ships; and much research seeks to refine that relationship (e.g., 17, 14, 16). However, the steeper hull angles of naval hull forms will likely delay the onset of flexural failure during an impact and thus will increase confining 
effects on ice-crushing mechanics. Therefore, the resulting pressure-area relationship could be substantially different from that recommended in the Polar UR.

Multiple impacts. The relatively slender bow shapes with a gradual increase in beam with station that are characteristic of naval hull forms increase the likelihood of multiple impacts of ice floes for each encounter. The Polar UR does not quantify effects of multiple impacts, although some research has been conducted to provide design guidance for ice-capable ships ([11, 18]). Nevertheless, the locations and severity of multiple sidehull impacts warrants specific attention for naval hull forms, as does the role of maneuvering on multiple impacts.

Tangential forces and friction effects. The Polar UR considers only normal forces resulting from ice impacts and does not include tangential forces arising from ice friction. Frictional forces could introduce important inplane stresses during ice impacts for the thin hull plating characteristic of naval vessels. Tangential forces and their variation with impact parameters thus warrant detailed investigation for naval hull forms.

Stochastic considerations. The Polar UR does not cast its design guidance in a statistical framework although independent research offers several good methods to do so (e.g., 19, 20, 21, 22). The natural variability in ice properties yields important variations in predicted design loads.

Conservative choices for the ice-related parameters can then lead to overly conservative design loads. Alternatively, a statistical formulation for iceimpact parameters can reduce conservatism to deliberately chosen levels (e.g., the largest load expected given 10,000 impacts). Furthermore, because ship speed affects ice-encounter frequency in partial ice cover, it has a direct influence on return-period statistics for ice-impact forces. Also, although maneuvering through low-concentration ice cover could reduce intentional ice impacts, it could also increase the risk of accidental impacts. That is, safe-speed and best-practice maneuvering guidance for Navy ships in ice should be cast in statistical terms. 


\section{Discrete Element Method}

The discrete element method (DEM) is a numerical approach to describe the dynamics of systems that contain large numbers of discrete elements and for which the effects of element-to-element interaction significantly influence the mechanical behavior of the bulk material. The DEM has been successfully applied to model sea ice processes such as pressure ridging [23], aggregation due to wave-ice interaction [24], and the mesoscale evolution of the floe size distribution [25]. Using the DEM, our model treats sea ice as a collection of discrete pieces of ice, thus affording the method certain advantages over the continuum approach for highresolution, high-fidelity modeling of sea ice dynamics. This is especially true for estimating ice loads on ships and offshore structures where fracture dynamics play a significant role in determining the peak ice-ship interaction stresses by inducing temporal and spatial discontinuities in the internal stress distribution. These discontinuities manifest as sharp fluctuations in the ice loads felt by the ship. Due to the discrete nature of the ice pack, especially at lower ice concentrations, ship-ice collisions are intermittent and occur in a small interaction area resulting in small, localized areas of high-impact stress. The CRREL sea ice model is well suited to capture the impulse-like nature of the ice interaction forces due to the model's explicitly discrete description of the ice cover, where the properties can be specified at the individual floe level.

Our technical approach incorporates a detailed treatment of the physical properties of the ice and appropriate contact laws to describe the ice-ship contact behavior. For this study, we numerically modeled the interaction between a ship and an ice floe as the intersection between a dilated polyhedron (ice floe) and undilated polyhedron (ship hull) that uses a modified Hertzian contact law to resolve the interaction forces.

\subsection{Dilated polyhedra}

For the ship and ice interaction problem, we represent the ship hull as a polyhedron defined by a triangulated surface and the ice floe as a dilated polyhedron. The dilated polyhedron is used for examining contact behavior and load evolution between two bodies in a numerically efficient manner by reducing contact detection to distance calculations as opposed to resolving the intersection surface and volume. The type of dilated polyhedron is the Minkowski sum of a polyhedron (base geometry) and a 
sphere (dilating geometry) with a radius denoted as the dilation radius (see Figure 5a). Each triangle of the ship hull defines a potential contact plane. When the distance between a surface triangle (ship hull) and an undilated polyhedron (ice floe) is less than the dilation radius, these two bodies are then said to be in contact, seen in Figure 5b. The contact generates interaction forces that vary according to a modified Hertzian model with a parallel viscous damping and a Coulomb friction cap on the tangential force.

Figure 5. Illustration of the dilated polyhedron and the contact condition. A dilated polyhedron is constructed using a polyhedron as the base geometry and extending the surface normally by a distance specified by the dilation radius, as shown in (a). When the base geometries of two bodies are less than the dilation radius, the bodies are said to be in contact, as shown in (b). The interaction forces between the two bodies is a function of the penetration depth.

\section{Contact detail}

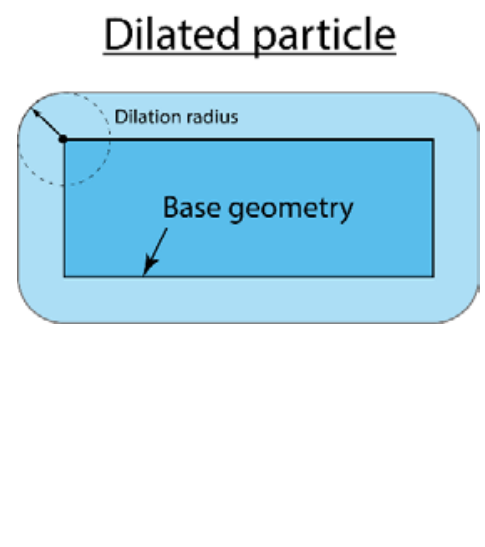

(a)

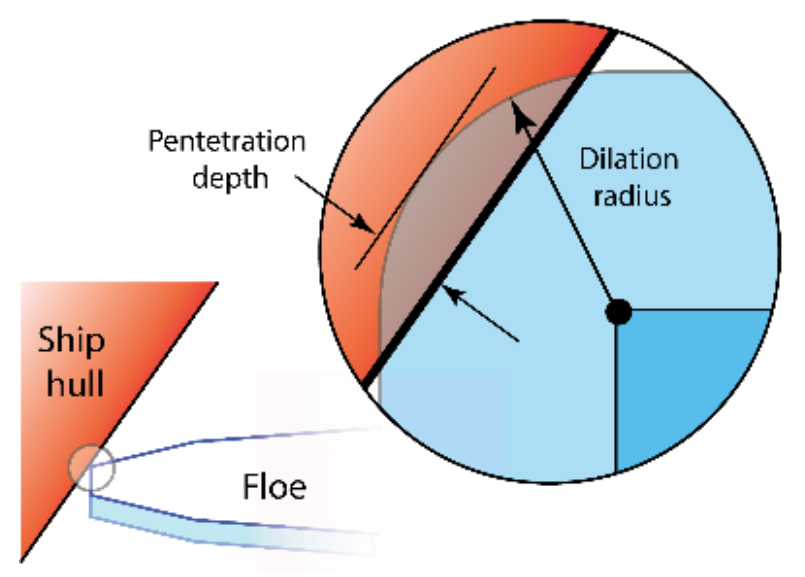

(b)

The force components depend on the overlap, or penetration depth, between the two bodies. The penetration depth, between bodies in a contact pair is defined as

$$
\delta=|\vec{d}|-R<0
$$

where $|\vec{d}|$ is the magnitude of the vector that defines the distance between the two undilated body geometries and $R$ is the dilation radius for the dilated body. 
The normal component of the contact force is calculated using a Hertzian contact force model similar to the one used by Lin and $\mathrm{Ng}$ [26], which extended the model developed by Johnson [27]. The contact force in the Hertzian model develops according to a non-linear force-displacement relationship that accounts for the increased contact area between elastic bodies as the normal interaction load increases. The equation for the normal contact force, $\overrightarrow{F_{n}}$, on the ship hull, as a function of the ice floe penetration depth, $\delta$, and relative velocity, $\vec{V}_{2 \rightarrow 1}$ is

$$
\overrightarrow{F_{n}}=-\left[\frac{2 \sqrt{2} G}{3(1-\nu)} R^{1 / 2} \delta^{3 / 2}-b_{n}\left(\vec{V}_{2 \rightarrow 1} \cdot \vec{n}\right)\right] \vec{n}
$$

where $G, v$, and $b_{n}$ are the shear modulus, Poisson ratio and damping coefficient, respectively, for the material of interest, which for this study is sea ice, and $\mathrm{R}$, is the ice floe dilation radius. The contact normal direction is defined to be pointing from the ship hull to the ice floe and the relative velocity is defined to be relative to the ship hull.

Coulombic frictional forces act between the ice and the ship hull. The frictional contact force $\overrightarrow{F_{t}}$ at time $m$ is calculated incrementally from the force at the previous time step $(m-1)$ as

$$
\vec{F}_{t}^{m}=\vec{F}_{t}^{m-1}-\left(k_{t} \Delta t-b_{t}\right)\left[\vec{V}_{2 \rightarrow 1}-\left(\vec{V}_{2 \rightarrow 1} \cdot \vec{n}\right) \vec{n}\right]
$$

where $k_{t}$ and $b_{t}$ are the tangential contact stiffness and damping, respectively, and $\Delta t$ is the time step. The dependence of the tangential stiffness on the normal force ([26]) determined by

$$
k_{t}=\frac{2\left[3 G^{2}(1-\nu) F_{n} R\right]^{1 / 3}}{2-\nu}
$$

Once the frictional force, $\overrightarrow{F_{t}}$, exceeds the Coulomb limit, sliding at the hullice interface begins. This condition can be written more formally as follows:

$$
\text { if }\left|\vec{F}_{t}^{m+1}\right|>\mu\left|\vec{F}_{n}^{m+1}\right| \text {, then }\left|\vec{F}_{t}^{m+1}\right|=\mu\left|\vec{F}_{n}^{m+1}\right|
$$

where $\mu$ is the coefficient of friction. The tangential contact force (using Eq. 6) is calculated incrementally to account for changes in the direction of 
the tangential component of the relative velocity and changes that the normal contact force produces in the tangential stiffness.

After the contact and body forces for each ice floe are determined, the accelerations (determined from the interaction and body forces) and velocities are integrated with respect to time for one time step to determine the new positions and velocities.

During the simulation, the time step is adjusted dynamically using the equation

$$
\Delta t=\frac{\pi}{10} \sqrt{\left(\frac{M}{k_{e f f}}\right)_{\min }}
$$

where $M$ is the mass of the ice floe in a contact and the effective contact stiffness $k_{\text {eff }}$ is defined as

$$
k_{e f f}=\frac{2 \sqrt{2} G}{3(1-\nu)} R^{1 / 2} \delta^{1 / 2}
$$

\subsection{Cohesive beam}

Simulations using a discrete element method commonly model particle-toparticle interactions as being governed by contact only (e.g. a Hertzian contact law). This modeling approach is valid when it can be assumed that the ice does not experience large scale fracture events during impact and that the pressures that develop during the crushing process are adequately parameterized as a function of penetration depth. To better understand the crushing and fracture processes in ice-ship impacts, we extended our particle-to-particle interactions to include cohesive bonding by adopting the method developed by Andre and coworkers [28]. Because we are using a discrete element model to approximate a continuous medium, we need cohesive interactions between the particles to appropriately model the continuum.

In the approach of Andre and coworkers, a "cohesive beam", which is not explicitly modeled, extends from particle centroid to particle centroid and defines the particle-to-particle interaction, as illustrated in in Figure 6. 
The cohesive beam is modeled as an Euler-Bernoulli beam, with the forces, $F$, and torques, $T$, acting on the particles described by

$$
\begin{gathered}
\mathbf{F}_{\mathbf{1}}=E A \frac{\Delta l}{l_{0}} \mathbf{X}-\frac{6 E I}{l_{0}^{2}}\left(\left(\theta_{2 z}+\theta_{1 z}\right) \mathbf{Y}+\left(\theta_{2 y}+\theta_{1 y}\right) \mathbf{Z}\right) \\
\mathbf{F}_{\mathbf{2}}=-E A \frac{\Delta l}{l_{0}} \mathbf{X}+\frac{6 E I}{l_{0}^{2}}\left(\left(\theta_{2 z}+\theta_{1 z}\right) \mathbf{Y}+\left(\theta_{2 y}+\theta_{1 y}\right) \mathbf{Z}\right) \\
\mathbf{T}_{\mathbf{1}}=\frac{G I_{0}}{l_{0}}\left(\theta_{2 x}-\theta_{1 x}\right) \mathbf{X}-\frac{2 E I}{l_{0}}\left(\left(\theta_{2 y}+2 \theta_{1 y}\right) \mathbf{Y}-\left(\theta_{2 z}+2 \theta_{1 z}\right) \mathbf{Z}\right) \\
\mathbf{T}_{\mathbf{2}}=-\frac{G I_{0}}{l_{0}}\left(\theta_{2 x}-\theta_{1 x}\right) \mathbf{X}-\frac{2 E I}{l_{0}}\left(\left(2 \theta_{2 y}+\theta_{1 y}\right) \mathbf{Y}-\left(2 \theta_{2 z}+\theta_{1 z}\right) \mathbf{Z}\right.
\end{gathered}
$$

where $F_{1}$ is the centroidal force acting on the first particle, $F_{2}$ is the centroidal force acting on the second particle, $E$ is Young's modulus, $A$ is the cross-sectional area of the beam, $\Delta l$ is the change in beam length along the $\mathrm{X}$ direction, $l_{o}$ is the original length of the beam, $I$ is the moment of inertia, $G$ is the shear modulus, and $I_{O}$ is the polar moment of inertia. The angles $\theta_{1}$ and $\theta_{2}$ are the angle vectors defined as $\theta_{1}=\left(\theta_{1 x}, \theta_{1 y}, \theta_{1 z}\right)$ and $\theta_{2}=$ $\left(\theta_{2 x}, \theta_{2 y}, \theta_{2 z}\right)$. These angles are created when rotating about the $\mathrm{X}, \mathrm{Y}$, and $\mathrm{Z}$ frame to align vectors $\mathrm{X}$ and $\mathrm{X}_{\mathrm{p}}$ as shown in Figure 6 .

Figure 6. Two discrete element particles with a cohesive beam (blue) connecting their centroids. The local particle coordinate systems are shown in red while the beam coordinate system is shown in green. The angle vectors $\theta 1$ and $\theta 2$ are used to calculate beam bending and torsion.

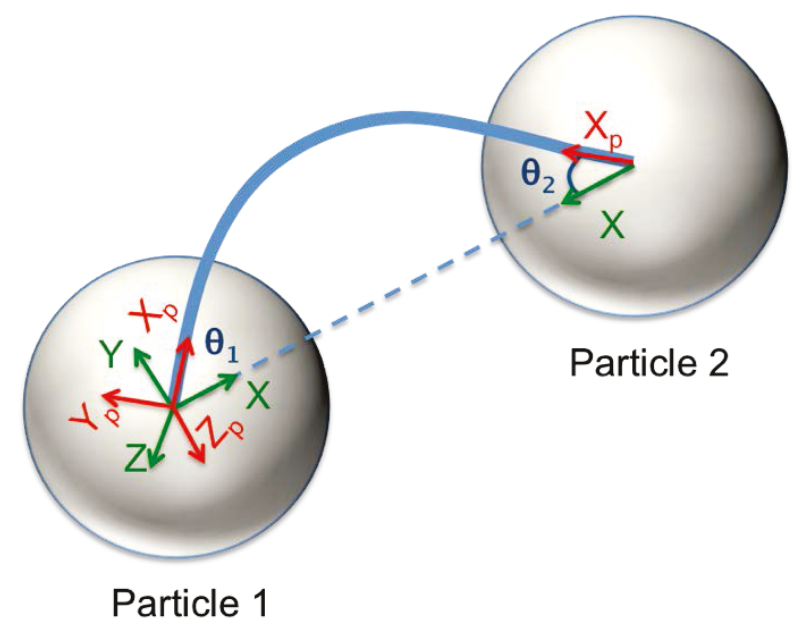


We extend the cohesive beam approach of Andre et al. [28] to include a cohesive beam failure criterion to be able to model the breakup of sea ice. To model the failure, we adopt the approach by Carmona et al. [29] where

$$
\left(\frac{\varepsilon_{x}}{\varepsilon_{t h}}\right)^{2}+\frac{\max \left(\left|\theta_{\mathbf{1}}\right|,\left|\theta_{\mathbf{2}}\right|\right)}{\theta_{t h}} \geq 1 .
$$

This failure model takes into account the axial beam strain $\varepsilon_{x}=\Delta l / l_{o}$, the max of the bending/torsion angles $\theta_{1}$ and $\theta_{2}$, and compares them to threshold variables $\varepsilon$ th and $\theta_{t h}$. If the sum of the strain and bending/torsion ratios exceeds 1.o, the beam fails, and subsequent particle interaction is only through contact. The threshold strain, bending angle threshold, Young's modulus, and shear modulus were set to values that reproduce the deformation and failure seen in sea ice measurements compiled in Timco and Weeks [30]. 


\section{Results}

\subsection{Goals and objectives}

Using a DEM-based ice-ship impact model, we conducted the following numerical studies as part of this effort:

- A comparison of estimated ice loads for naval and ice breaking hull forms.

- A comparison of stem-on versus side impact load development when using a fracture-capable impact model.

This modeling effort aids the prediction and evaluation of ice loads on naval hull forms not only by informing structural considerations, such as optimal locations for hull reinforcement, but also providing insight into safe operation in the presence of ice. For example, physical model experiments and preliminary numerical model results show that stem-on collisions that split floes have lower peak loads than side panel impacts, suggesting avoidant maneuvers may be more dangerous for thin skinned naval vessels. This study closely examined the relationship between impact locations to provide better insight into the potentially counterintuitive consequences of navigation behaviors, in particular ice side impact scenarios.

\subsection{Ice impact loads comparison between icebreaking and combatant hull forms}

Although ice impact load estimation for a naval hull form is the primary focus of the overall study presented in this report, we include the estimated ice impact loads using the same DEM model on an icebreaking hull form as a point of reference. The naval hull form used in this study is the Hull 3000, which is a conceptual naval combatant that was developed for the purpose of collaborative study between academic, industry, and U.S. Navy partners. The icebreaker hull form used for comparison is the USCG Polar Sea/Star which is a heavy icebreaker that was commissioned in 1977. The parameters for both ships are listed in Table 1. 
Table 1. Ship study parameters.

\begin{tabular}{|c|c|c|c|c|c|}
\hline \multicolumn{3}{|c|}{ Polar Sea/Star parameters } & \multicolumn{3}{|c|}{ Hull 3000 parameters } \\
\hline Parameter & Value & Units & Parameter & Value & Units \\
\hline Length $_{O A}$ & 129.5 & meters & Length $_{O A}$ & 125.3 & meters \\
\hline Length $_{W L}$ & 120.0 & & Length $_{1}$ & 122.4 & \\
\hline $\operatorname{Beam}_{W L}$ & 24.1 & meters & $\operatorname{Beam}_{W L}$ & 15.3 & meters \\
\hline Depth & 18.0 & & Depth & 11.2 & ers \\
\hline Draft & 9.4 & meters & Draft & 4.4 & meters \\
\hline
\end{tabular}

Both ships are comparable in length but are quite distinct with respect to the maximum beam dimension, where the Polar Sea is nearly 10 meters wider at the waterline than the Hull 3000. The Polar Sea's wider beam is presumably for stability and to accommodate the rounded, spoon-shaped bow that is characteristic of icebreaking hull forms. The bow shape promotes downward deflection, therefore flexural failure of the ice, thus, decreasing the ice impact loads and power requirements for the icebreaking ship. But, this larger hull angle with respect to the centerline means that the impacts are not as glancing as would occur with the more slender Hull 3000 and it does not allow the ice to clear away from the ship as freely.

\subsubsection{Ice floe geometry and properties}

For this set of numerical experiments, we examine the forces generated from a corner impact of a 12-sided floe (see Figure 7) with a ship hull, where the floe corner angle bisector is oriented perpendicular to the hull's tangent line at the impact location. This ship-floe configuration should represent the worst-case impact scenario (i.e., the orientation that results in the highest impact forces).

Figure 7. Floe geometry.

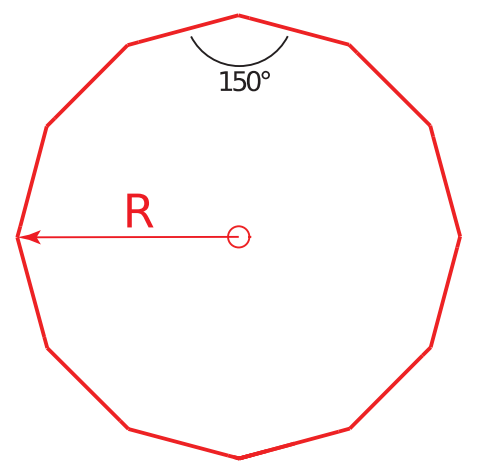


The force imparted on a ship due to impact with an ice floe is dependent on many factors (e.g., ice thickness, ice density, ice type, ship speed, maneuver type, etc.). In this study, however, we focus on impact location and ship speed as the experiment parameters of interest and keep the ice floe dimensions and properties constant, which are enumerated in Table 2. The ice parameters used in this study are representative of fairly compromised and warm first-year ice, similar to the ice encountered in summer conditions in the marginal ice zone.

Table 2. Ice parameters.

\begin{tabular}{lcl}
\hline Parameter & Value & Units \\
\hline Ice density, $\rho_{\text {ice }}$ & 900.0 & $\mathrm{~kg} / \mathrm{m}^{3}$ \\
Shear modulus, $G$ & 0.1 & $\mathrm{GPa}$ \\
Poisson ratio, $\nu$ & 0.31 & - \\
\# of sides & 12 & - \\
Wedge angle & 150 & degrees \\
Circumcircle radius, $R$ & 10.0 & meters \\
Thickness, $t$ & 0.5 & meters \\
Mass & 1.3 & $10^{5} \mathrm{~kg}$
\end{tabular}

\subsubsection{Polar sea impact forces}

Figure 8 shows the initial impact locations considered in this study, which ranged from 10 to 60 meters from the waterline bow location. For each impact location, the floe was positioned such that one corner of the 12sided floe was coincident with the ship hull at the specified location. Then, the floe was oriented so that the line from the corner vertex and the floe center was perpendicular to the ship hull tangent line, as illustrated in Figure 9. The ship's forward velocity was prescribed and ranged from 0.5 to 5.0 meters per second and did not vary throughout the numerical experiments, since the ship's motion was prescribed, therefore was not affected by interaction with the ice floe. Each numerical experiment would proceed through impact until the ship and floe were no longer in contact (i.e., the impact force was equal to zero). For this study, we only consider the forces generated during a single impact event and ignore subsequent impact events with the same floe. However, multiple impact scenarios may be important to fully understand the probabilities of impact force levels at particular locations along the ship's hull. 
Figure 8. Impact location map on the Polar Sea.

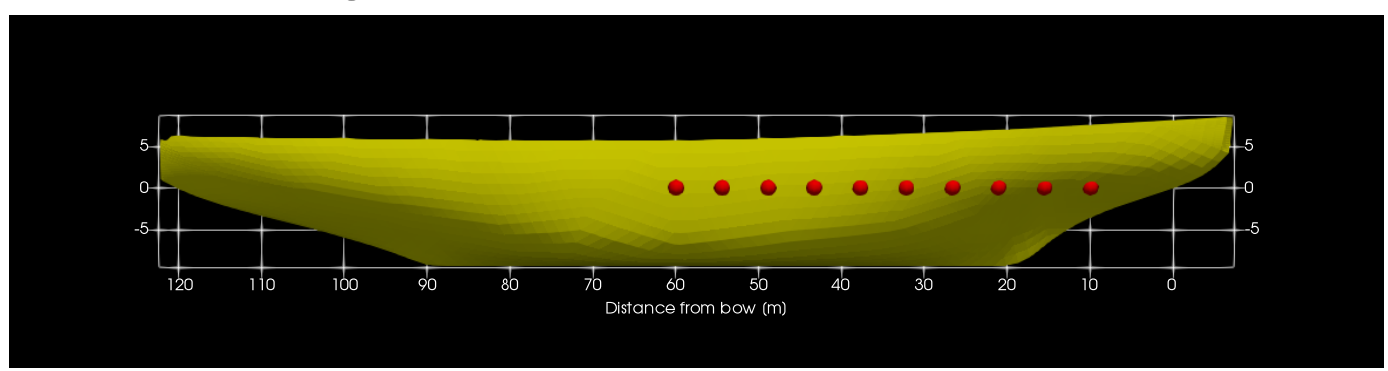

(a) Side View

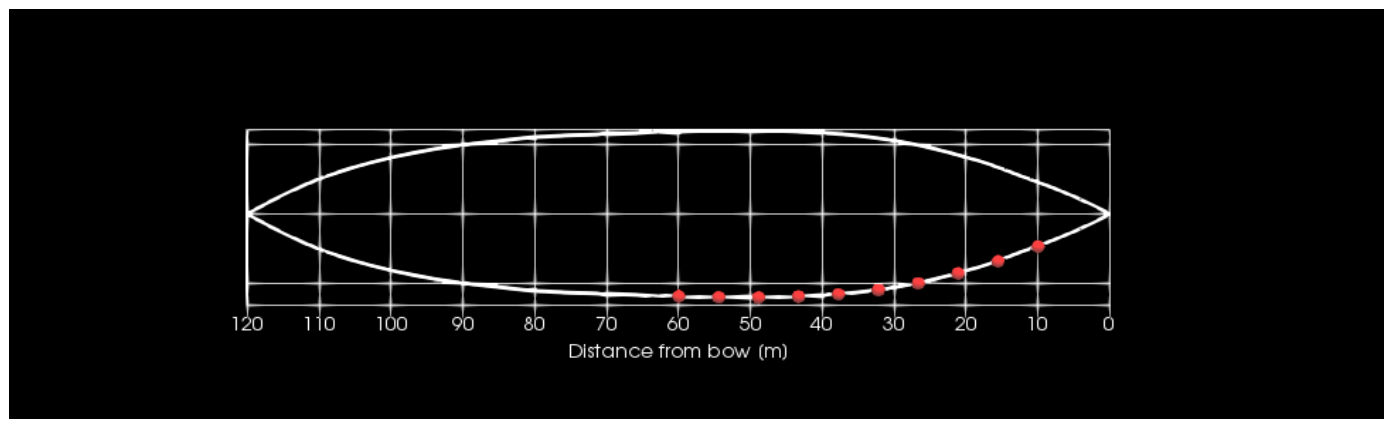

(b) Waterline View

Figure 9. Floe impact setup.

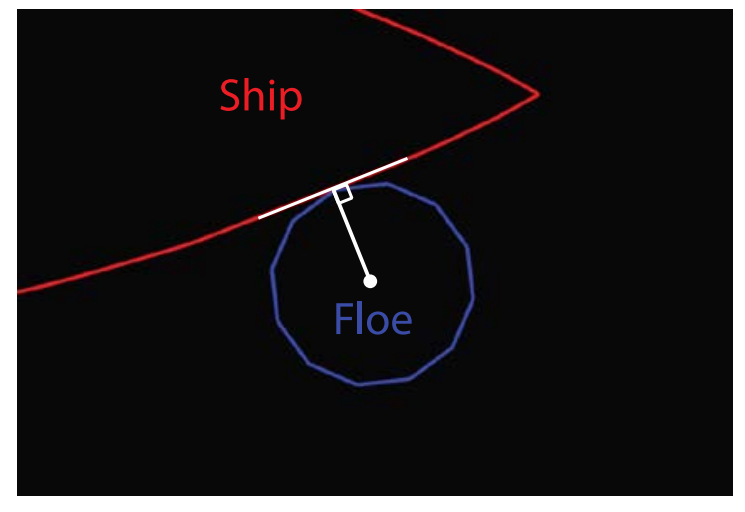

The time evolution of the impact force at $x_{\text {contact }}=10 \mathrm{~m}$ (impact location relative to the bow) presented in Figure 10 is representative of the behavior seen over the set of ship speeds and locations considered. In each case, the impact forces rise as the ship moves forward, initiates contact, then is increasing contact with the ice floe. This impact force plateaus when the ship and floe reach their maximum interpenetration distance, or when enough momentum has been transferred from the ship to the ice floe so that the floe's relative velocity is directed away from the ship. For the locations near the bow, some of the impact force is directed in the vertical direction rather than in the plane of the free surface, therefore the floe is unable to escape from the ship's path, which tends to extend contact times. 
In the $u_{\text {ship }}=1.0 \mathrm{~m} / \mathrm{s}$ case, the floe is in contact for nearly 2 seconds in contrast to the $u_{\text {ship }}=5.0 \mathrm{~m} / \mathrm{s}$ case, where the contact lasts approximately 0.30 seconds because of the significantly larger impact force, which allows the floe to clear the ship's path sooner. We observe high frequency noise in the impact force versus time signal especially at higher ship velocities that we attribute to mesh effects.

Figure 10. Impact force time trace for Polar Sea at $10.0 \mathrm{~m}$ from bow.

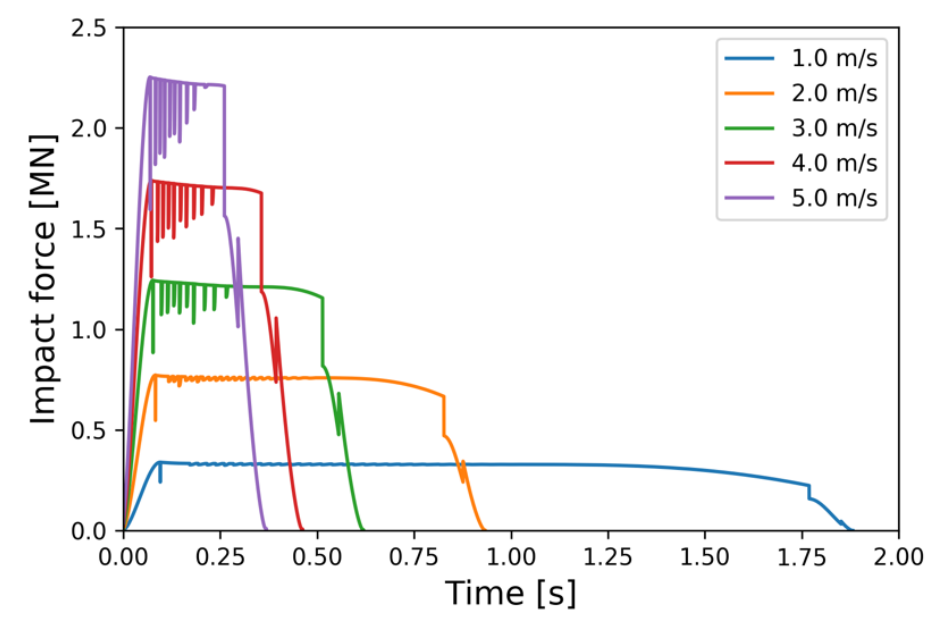

Figure 11 shows the impact force as a function of initial impact location.

For all locations and ship speeds, the impact force does not exceed 3.o MN for locations near the bow, where the hull angle with respect to the centerline is near a maximum for this hull form, it gradually decreases as the hull angle with the centerline decreases, then quickly drops to insignificant levels $\left(F_{\text {impact }}=86 \mathrm{~N}\right.$ ) between 40 and 50 meters from the bow as we near the maximum beam location where the hull tangent line is parallel to the centerline. We do not plot results for locations aft of the maximum beam location $\left(x_{\text {maxbeam }}=52.0 \mathrm{~m}\right)$, since the ship simply moves away from the ice floe for these locations. 
Figure 11. Polar Sea ice impact forces as a function of distance from the bow.

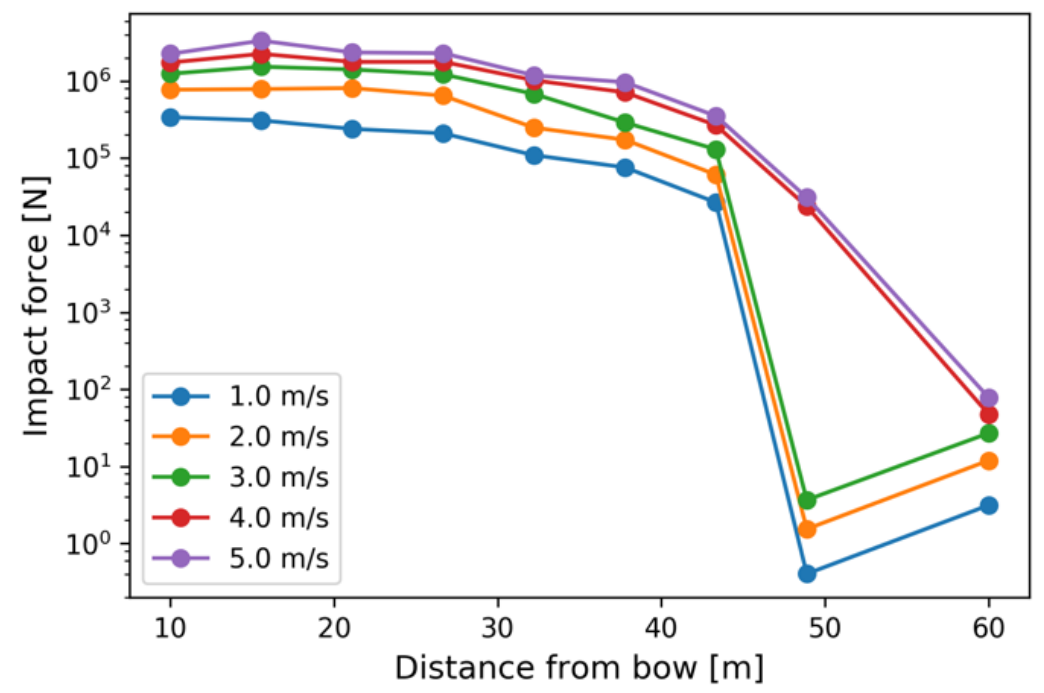

\subsubsection{Hull 3000 impact forces}

For the Hull 3000, impact simulations were conducted for 40 locations uniformly distributed between 10 and 60 meters from the bow's waterline location, as illustrated in Figure 12. In the near bow region, there is a concave region due to the bulb, which can move the impact location from above the water's surface to below, as illustrated in Figure 13. This range of impact locations was selected intentionally to avoid complications that arise due to the bow bulb.

Figure 14 illustrates a typical time trace of the impact force as a function of time. In comparison with the Polar Sea impacts, the Hull 3000 impacts are much shorter in duration and do not exhibit the plateau region. The short duration of the impacts indicates that the Hull 3000 transfers enough momentum in the free surface plane to immediately push the floe away from the hull due to the more vertical sides of the Hull 3000. The time trace exhibits high frequency oscillations, similar to those seen with the Polar Sea, that occur when the contact point between the floe and ship oscillates between two facets on the hull form mesh. We anticipate that efforts to improve the mesh quality (i.e., improve the size distribution and reduce the relative facet angles) will smooth out this behavior, but we do not expect that the impact force magnitudes will vary significantly from those observed here.

The impact force as a function of initial impact location is shown in Figure 15. The maximum impact force does not exceed $3 \mathrm{MN}$ for a forward ship 
speed of $5.0 \mathrm{~m} / \mathrm{s}$, and does not exceed $0.6 \mathrm{MN}$ for the $1.0 \mathrm{~m} / \mathrm{s}$ case, with the impact force decreasing just slightly as the impact location moves aft. In fact, the decrease in impact force is less than $10 \%$ between 10 and 50 meters from the bow for all speeds tested. For locations more than 40 meters from the bow, the hull angle with respect to the centerline drops sharply as we near the maximum beam and the impact force level drops another $10 \%$ between 50 and 60 meters from the bow. The impact force will drop to zero over the next 5 meters as we near the maximum beam location and the ship merely passes by the ice floe without actually hitting it.

Figure 12. Impact location map on the Hull 3000.

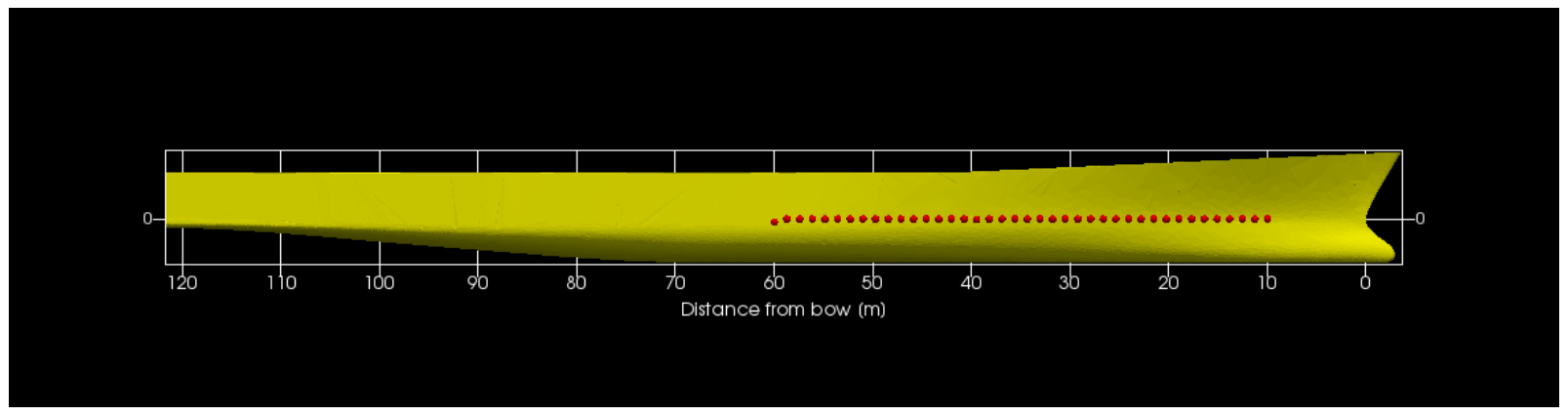

(a) Side view

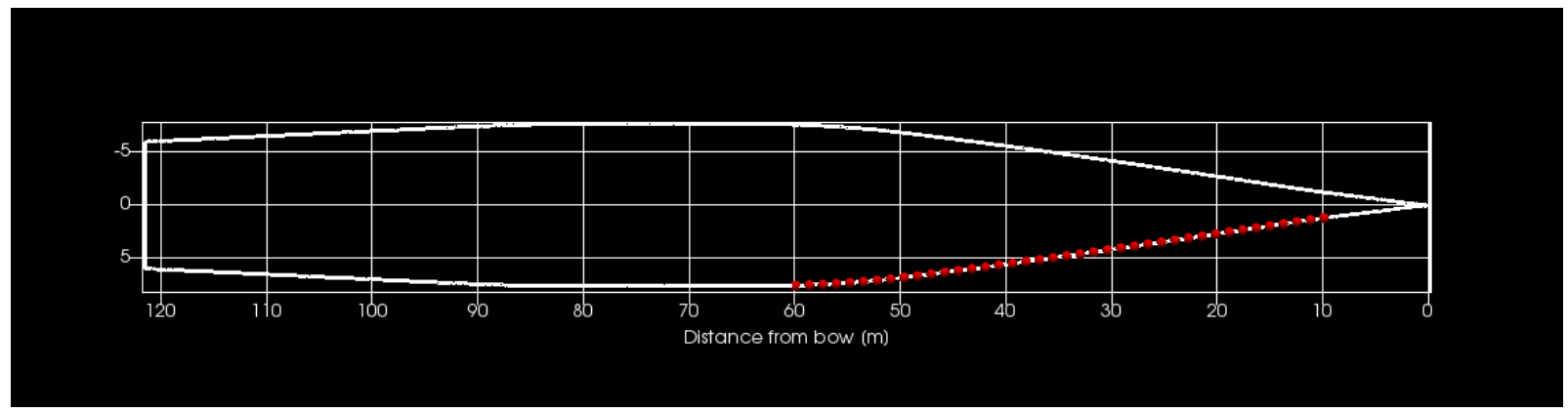

(b) Waterline view 
Figure 13. Detail of bulbous bow region. The region of concavity, which is indicated by a sharp transition of surface normal direction (i.e., red to blue), above the bow bulb will lead to multiple contact points between the ship and the hull. This is illustrated by a vertical line dropped from the specified impact location that has multiple intersection points.

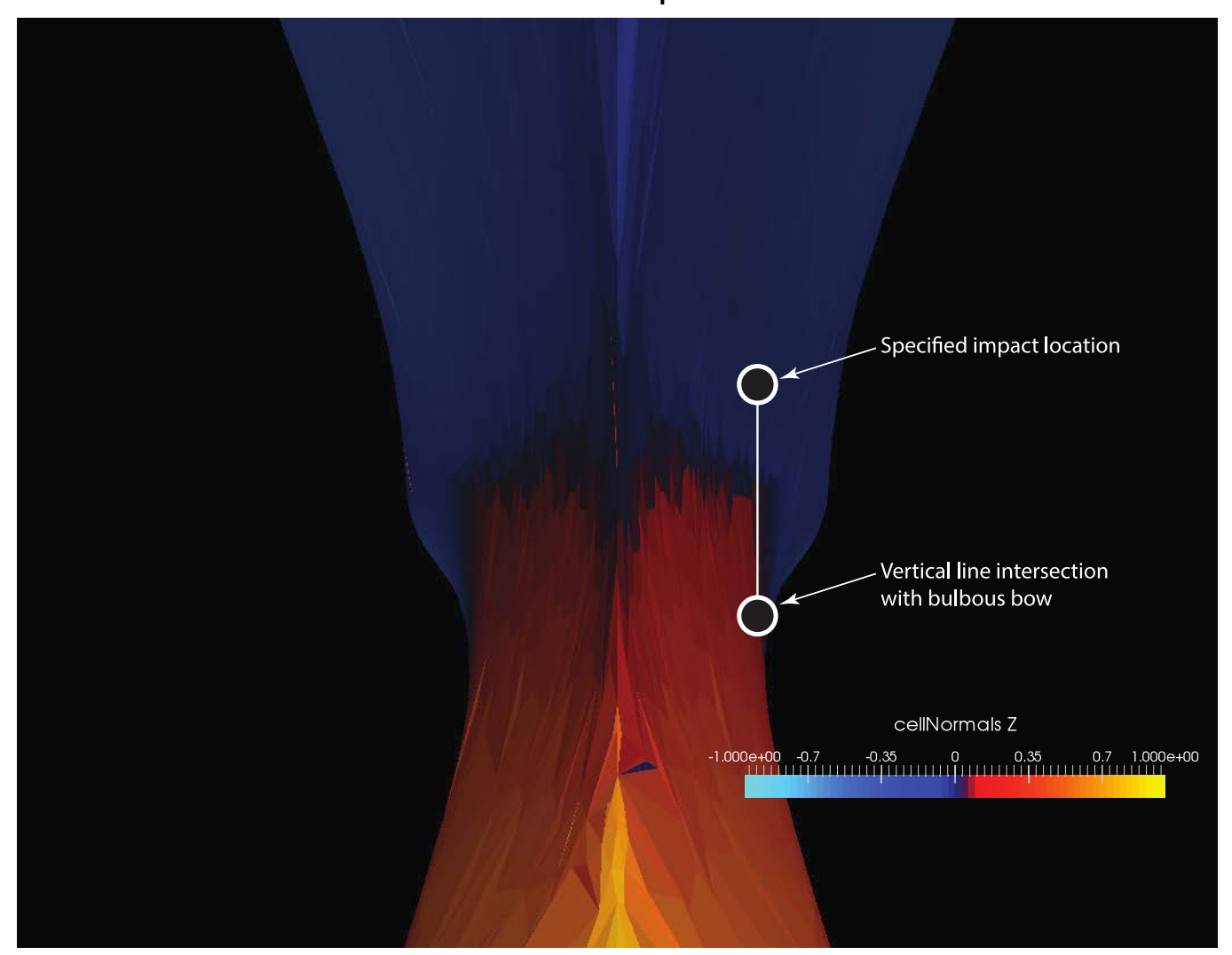

Figure 14. Impact force time trace for Hull3000 at $10.0 \mathrm{~m}$ from bow.

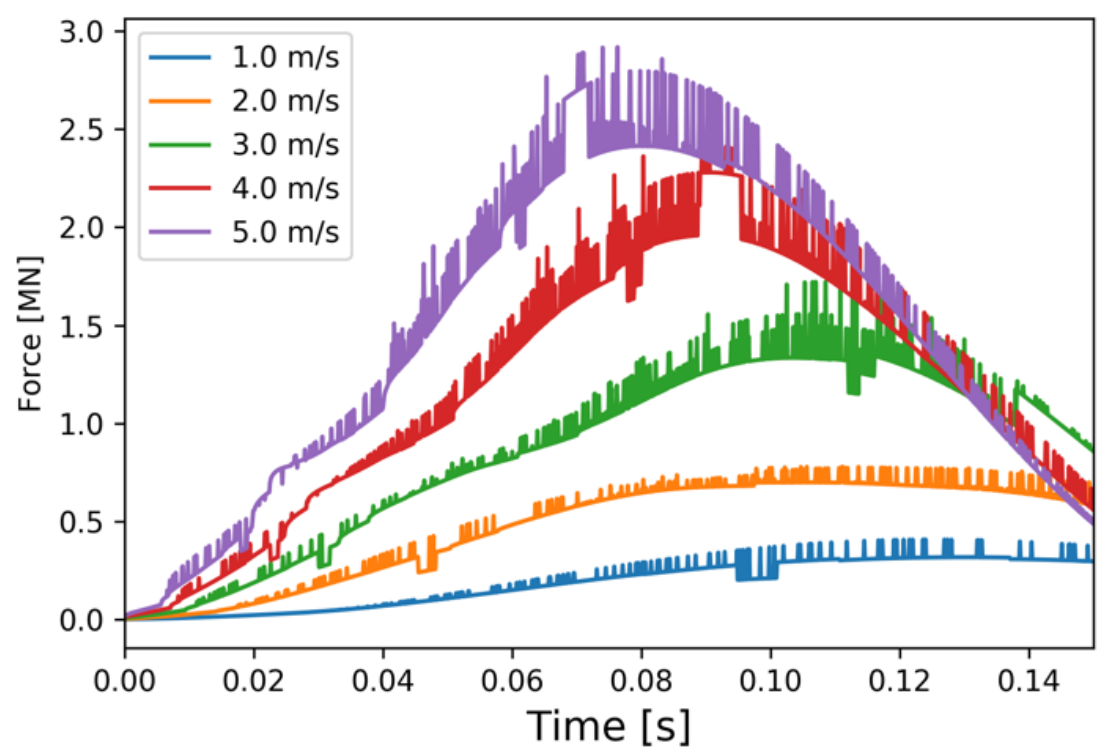


Figure 15. Hull3000 impact forces as a function of impact location.

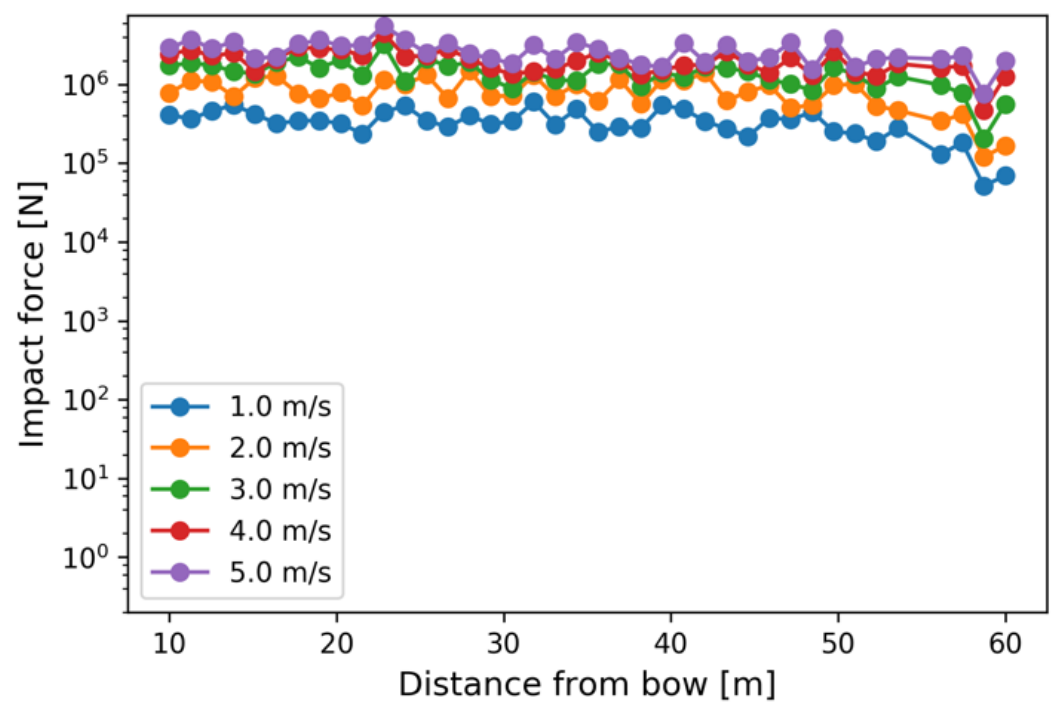

\subsection{High-resolution ice floe simulations}

A limitation of representing ice floes with polyhedra is that fracture and crushing are not represented directly and depend on parameterizations that adequately describe the fracture and crushing processes without changes to floe geometry. To model the fracture and crushing processes directly, we discretize individual ice floes as an aggregation of small parcels of ice. Neighboring ice parcels are bonded together using a cohesive beam formulation subject to failure strain criteria, which simulates the grain structure in a larger piece of ice. The particles also interact with each other through a Hertzian contact law allowing us to model the loads even when the regions of the floe have disaggregated. The detail in Figure 16 shows the regular packing of uniformly sized spheres for this particular floe configuration. To demonstrate the advantages of a DEM-based high-resolution ice impact model, we consider two impact scenarios: (1) a direct stem-on impact ( $\mathrm{x}$ contact $=0.0 \mathrm{~m}$ ) and, (2) a glancing impact ( $\mathrm{x}_{\text {contact }}=8.8 \mathrm{~m}$ ), as shown in Figure 17 with floe with a $5 \mathrm{~m}$ radius and $0.5 \mathrm{~m}$ thickness to match the single particle ice floe simulation ice parameters. 
Figure 16. Detail of high-resolution multiparticle ice floe.

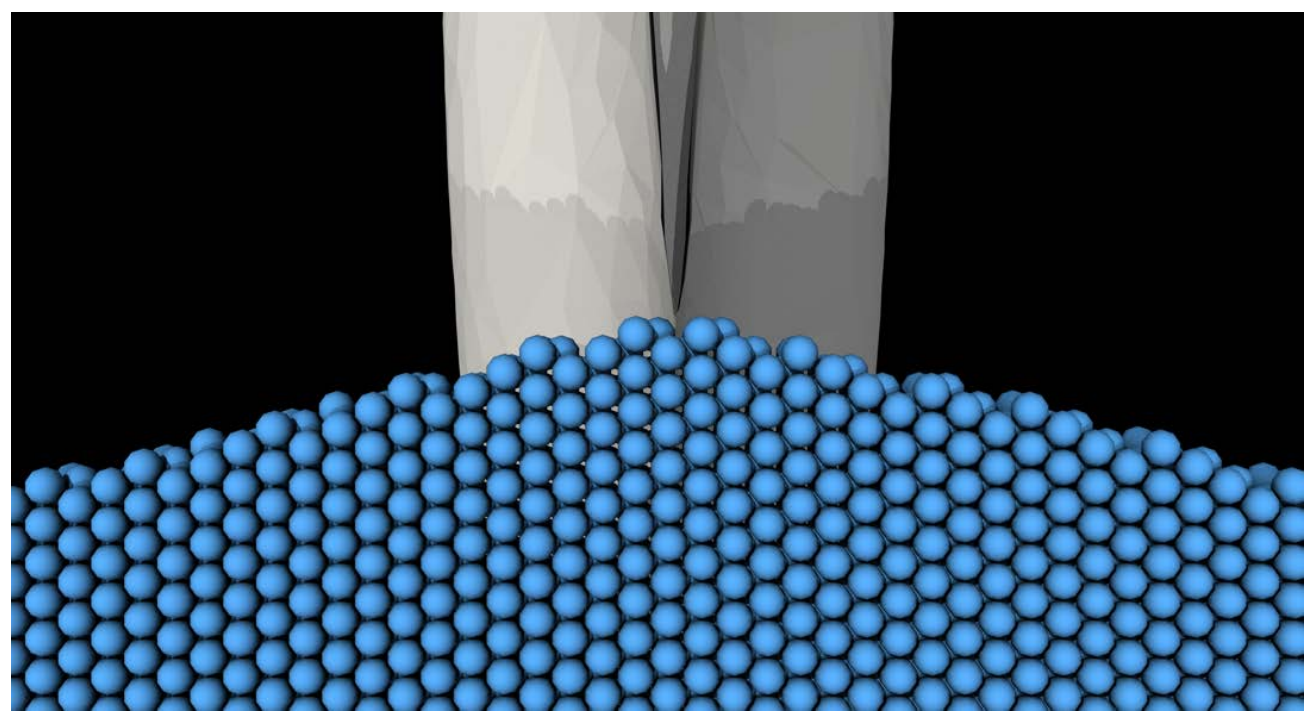

Figure 17. Illustration of the impact configurations for high-resolution simulations.

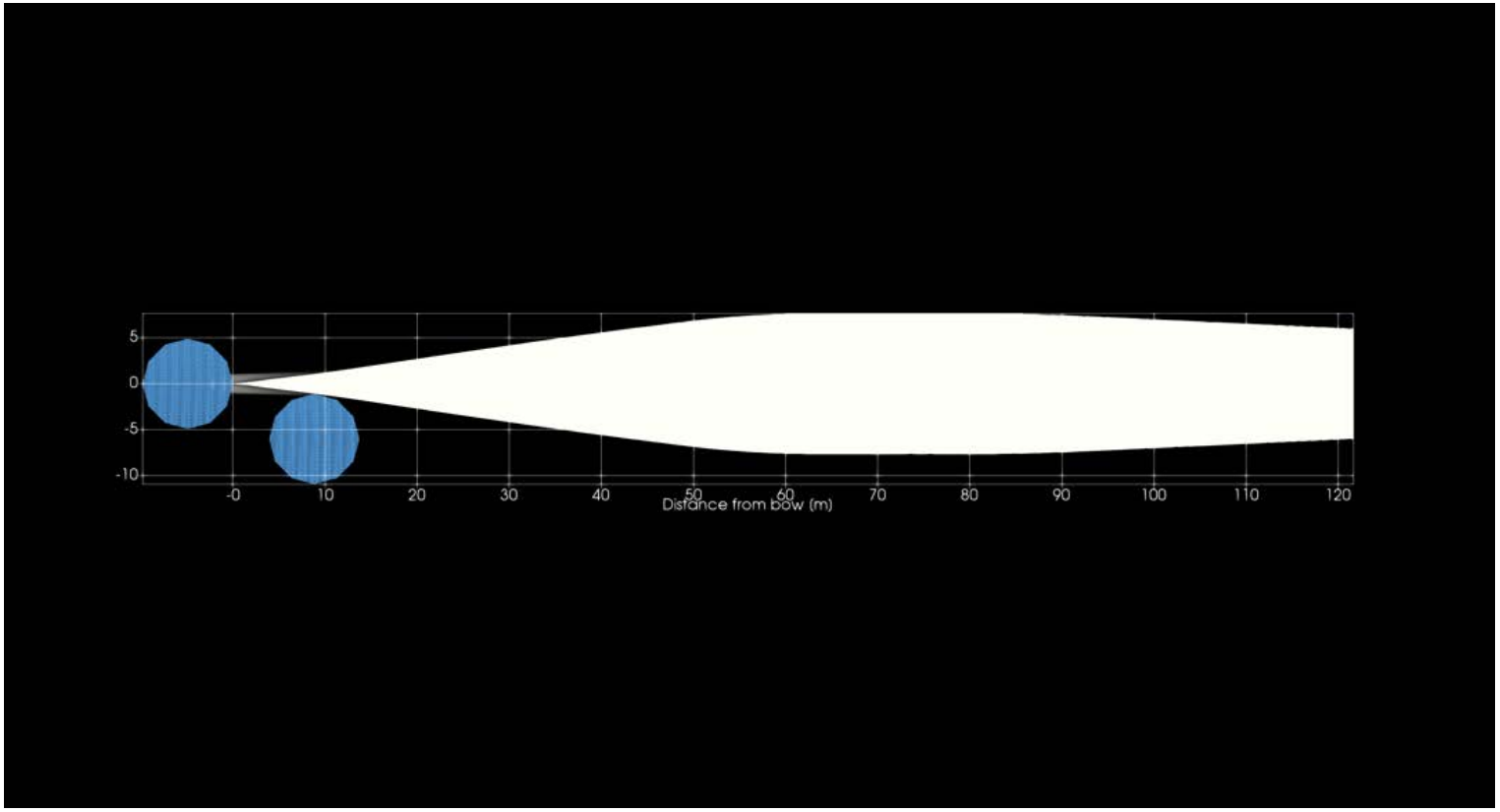

In this study, each high-resolution ice floe is composed of 24,953 spherical ice particles that have a radius of $10 \mathrm{~cm}$ that are bonded together with a cohesive beam (see Table 3 for cohesive beam parameters). For each case, the ship velocity was $u_{\text {ship }}=3.0 \mathrm{~m} / \mathrm{s}$. Figure 18 shows the impact force time evolution for the direct and glancing blow impacts with a high-resolution ice floe. For both cases, the impact force rises over a period of approximately $0.2 \mathrm{~s}$, reaches a maximum impact force level, and plateaus for the duration considered. The contrast between the two impact cases is particularly striking with the direct blow impact reaching a maximum of 
$0.35 \mathrm{GN}$ and the glancing blow impact reaching a maximum of $2.6 \mathrm{GN}$. This nearly order magnitude difference between the two cases is due to the difference in the way that the ship interacts with the floe during the impact process. For the glancing blow case, the impact process is similar to how the impact forces would evolve with a polyhedron particle. The floe stays intact, and the impact force is due to the momentum exchange that occurs through the interparticle contact law. But as seen in Figure 19, the direct blow case is a completely distinct process where we observe fracture at many length scales.

Table 3. Cohesive beam parameters.

Cohesive beam parameters

\begin{tabular}{lcl}
\hline Parameter & Value & Units \\
\hline Beam radius & 0.01 & meters \\
Elastic modulus & 10.0 & $\mathrm{MPa}$ \\
Poisson's ratio & 0.35 & - \\
Failure strain & 0.001 & - \\
Failure angle & 0.5 & radian
\end{tabular}

Figure 18. Comparison of impact forces between direct and glancing blows near bow.

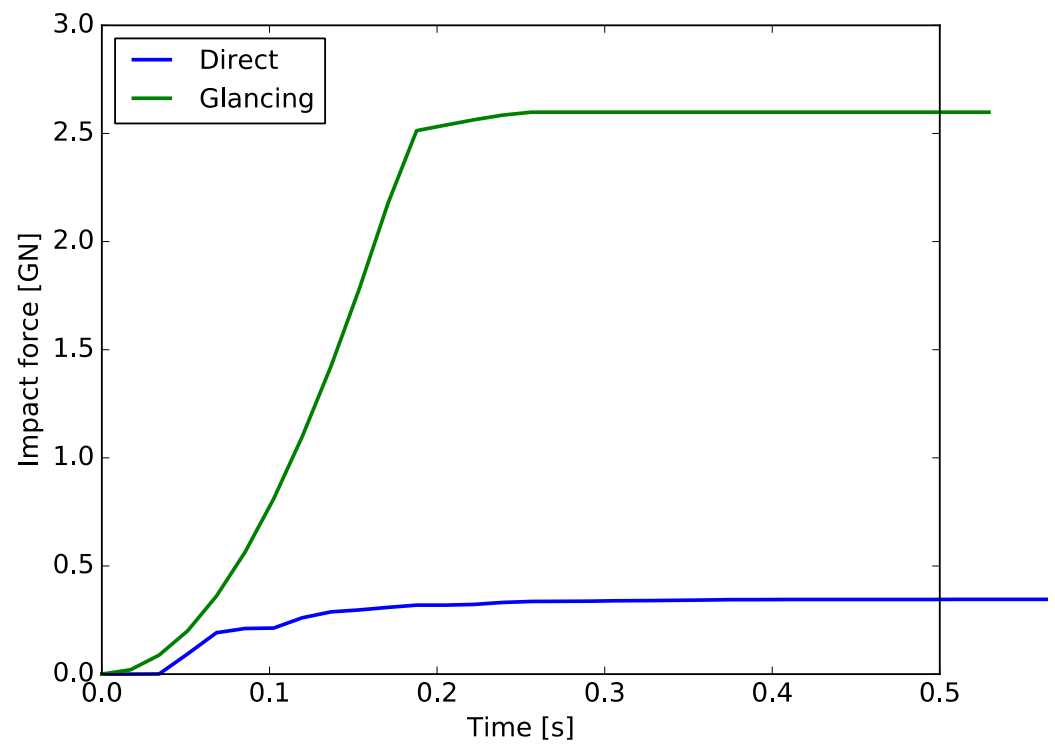


Figure 19. Detail images of stem-on impact with multiparticle floe.

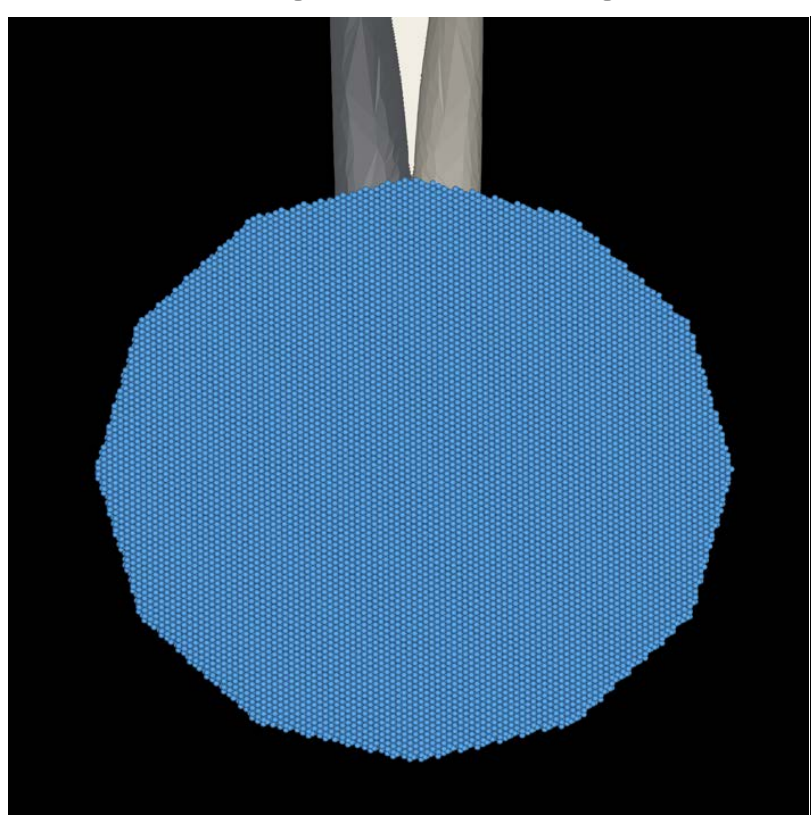

(a) $t=0.0$ seconds

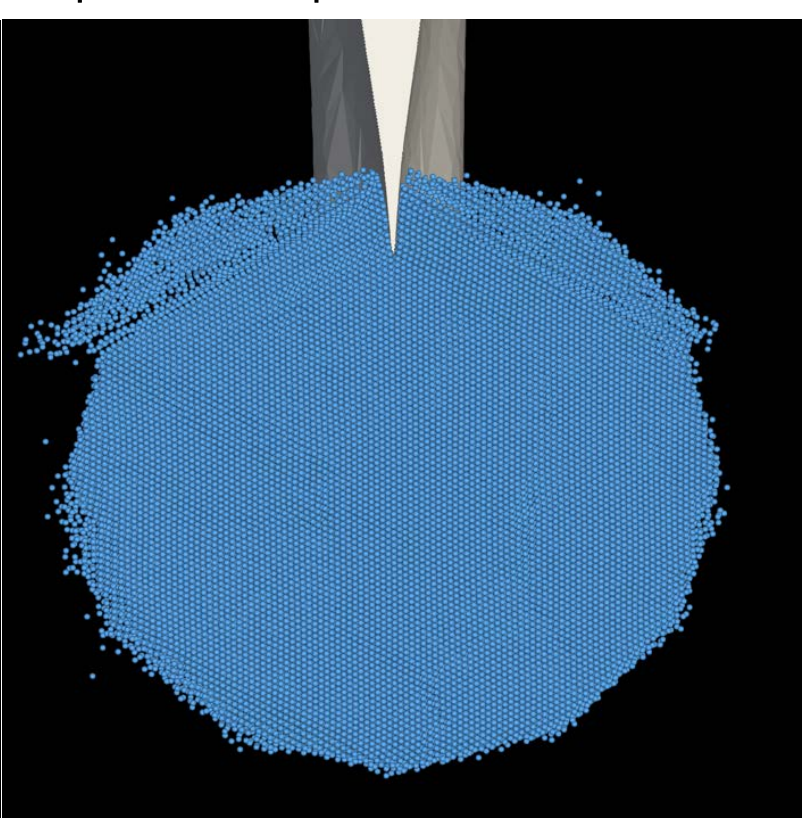

(b) $t=0.8$ seconds

In Figure 19b, we observe failure along shear planes located at equal angles from the crack initiation point (i.e., the ship stem), and a crack propagating ahead of the ship bow. These fractures, especially the crack that propagates ahead of the ship, reduces the total impact force because of the mechanical advantage due to the ship acting like a wedge to split the floe. The impact forces estimated in the high-resolution floe simulations are $10^{3}$ times higher than comparable impact scenarios in the single polyhedron simulations. We suspect that this is due in large part to the regular spherical packing that was used to generate the high-resolution floe geometry. This particle configuration results in a very stiff aggregate behavior because there are no lattice irregularities to facilitate relative translational motion between particles. Despite this current model limitation, the results are illustrative of the benefits of the multiparticle floe configurations. 


\section{Conclusions}

As the ice conditions in the Artic change and the amount of maritime activity in this region increases, the U.S. Navy will need to evaluate platform capabilities in marginal ice zone conditions. A primary concern is the level of impact forces when a ship encounters ice. Current ice impact models, such as the one used to develop the Polar UR, were developed for impact scenarios and hull forms more appropriate for Polar Class ships rather than naval hull forms. We present an alternative approach that uses the DEM approach to modeling the ice impact problem.

The ice impact forces on the Hull 3000, a conceptual naval combatant hull form, and the Polar Sea, a USCG heavy icebreaker, were estimated and compared using a single particle DEM model. Despite significant differences in the hull form geometries, most notably the Hull 300o's maximum beam dimension being nearly $10 \mathrm{~m}$ narrower than the Polar Sea, the maximum impact force levels are relatively similar for both hull forms and range from 0.3 to $2.5 \mathrm{MN}$ for ship speeds ranging from 1 to 5 $\mathrm{m} / \mathrm{s}$. The geometry differences show up mainly in the time evolution of ice impact forces. Since the Polar Sea has broader beam for roughly the same waterline length, the ship has a larger bow angle with respect to the centerline and is more prone to "plowing" through the ice, therefore the impact durations tend to be longer than impacts with the Hull 3000. The ice impacts with the Hull 3000 are primarily low angle glancing blows that are short in duration. Another reason for the similar force levels between the two types of hull forms is that this ice impact model does not take flexural failure into account, therefore the forces calculated with a single particle ice floe for the Polar Sea can reach unrealistically high levels.

Accurate modeling of the ice impact problem will require accommodation of flexural failure and an improved model for crushing, which a multiparticle representation of the floe geometry will accomplish. We compare a glancing and a direct, stem-on impact to illustrate the benefits of a high-resolution floe model that can easily accommodate fracture and crushing. A striking result is that the side impact force is nearly an order of magnitude higher than the stem-on impact, because with the stem-on impact, the ship acts like a wedge to split the ice floe. More work needs to be done to determine this result's validity. However, this dramatic difference between stem-on and side impacts may suggest a 
counterintuitive navigation behavior in marginal ice zones, meaning it may be safer to hit sufficiently small floes head on.

\subsection{Future considerations}

The set of numerical model results presented in this report provides a sense of the capabilities and strengths of a DEM-based ice impacts model in contrast to other collision models. For example, the DEM-based model does not make assumptions about the impact scenario and can readily perform a set of experiments where the ice properties, geometry, and orientation can be randomly sampled to generate realistic statistics for impact force magnitudes and impact locations. With these statistics, one could better assess operational risk due to given ice conditions and could focus new or retrofitted design to high risk areas on the hull. As an example, if stem-on impacts proved to have lower risk force magnitudes, the design efforts could focus on reinforcing the stem area for a ship that only operated in marginal ice zone conditions.

In addition, the DEM-based model could be used to model ice-ship impacts while underway in realistic marginal ice zone conditions. These simulations of an ice-laden seaway could be represented with a set of DEM elements, potentially initialized with remote sensing of regions that we expect naval vessels to operate in. This type of simulation could be used to better understand how to reduce impact risk when performing ice avoidance maneuvers and planning safe routes.

An important component to improving ice impact estimates is better understanding of the processes that ice undergoes during impact, primarily fracture and crushing. Using a DEM-based approach, we model these processes explicitly which allows us to model impact scenarios that do not have corresponding empirical data or a sufficient number of data to generate meaningful statistics. By modeling the microscale phenomena that contribute to the macroscale impact behavior, we will be able to provide physics-based impact load estimates.

Current pending model improvements include full coupling with a fluid dynamics solver, which will be especially important in accurately modeling the fluid-solid interaction that occurs during the crushing process and to incorporate effects to flow features such as the bow wave. We are also improving a modeling capability to couple the DEM ice model with a finite element method (FEM) based deformable body model. This allows us to 
better represent ice interaction with bodies that experience significant strain levels, including plastic strain. This full suite of coupled solvers accompanied with a series of well characterized and controlled ice impact experiments outlined in [1] will greatly improve the U.S. Navy's ability to estimate ice impact loads, provide a modeling framework for improving ship design for performance in ice-covered waters, and improve general knowledge in the processes underlying the ice impact problem. 


\section{References}

[1] Arnold J. Song, James H. Lever, and Sarah W. Bates. 2016. Modeling relevant to safe operations of US Navy vessels in arctic conditions: Physical modeling of ice loads. ERDC/CRREL SR-16-3. Hanover, NH: US Army Engineer Research and Development Center.

[2] Jerry M. Melillo, T.T. Richmond, and G. Yohe. 2014. Climate change impacts in the United States. Third national climate assessment 52.

[3] Mark C. Serreze and Jennifer A. Francis. 2006. The arctic amplification debate. Climatic Change 76(3-4):241-264.

[4] James A. Screen and Ian Simmonds. 2010. The central role of diminishing sea ice in recent arctic temperature amplification. Nature 464:1334-1337.

[5] Arun Kumar, Judith Perlwitz, Jon Eischeid, Xiaowei Quan, Taiyi Xu, Tao Zhang, Martin Hoerling, Bhaskar Jha, and Wanqui Wang. 2010. Contribution of sea ice loss to arctic amplification. Geophysical Research Letters 37(21).

[6] Rajendra K. Pachauri, Myles R. Allen, Vicente R. Barros, John Broome, Wolfgang Cramer, Renate Christ, John A. Church, Leon Clarke, Qin Dahe, Purnamita Dasgupta, et al. Climate change 2014: synthesis report. Contribution of Working Groups I, II and III to the fifth assessment report of the Intergovernmental Panel on Climate Change. Geneva, Switzerland: IPCC.

[7] US Navy. 2014. US Navy Arctic roadmap 2014-2030. Washington, DC: Department of the Navy. www. navy. mil/docs/USN arctic roadmap. pdf.

[8] IACS (International Association of Classification Societies). 2011. Requirements Concerning Polar Class. London: International Association of Classification Societies, Ltd.

[9] Yu N. Popov, O.V. Faddeev, D.E. Kheisin, and A.A. Yakovlev. 1969. Strength of ships sailing in ice. Report No. FSTC-HT-23-96-68. Charlottesville, VA: Army Foreign Science and Technology Center.

[10] John Dolny, Han-Chang Yu, Claude Daley, and Andrew Kendrick. 2013. Developing a technical methodology for the evaluation of safe operating speeds in various ice conditions. In Proceedings of the International Conference on Port and Ocean Engineering Under Arctic Conditions.

[11] C.G. Daley and J.J. Liu. September 2010. Assessment of ship ice loads in pack ice. In International Conference and Exhibition on ships and structures in ice (ICETECH10). Alexandria, VA: Society of Naval Architects and Engineers (SNAME).

[12] J.W. St. John, C. Daley, and Harold Blount. 1984. Ice loads and ship response to ice. Summer 1982/Winter 1983 test program. Report No. SSC-329. Washington DC: Ship Structure Committee. 
[13] Edward A. Devine, Devinder S. Sodhi, et al. 1992. Preliminary results of the US Navy localized ice impact test program. In The Second International Offshore and Polar Engineering Conference. Mountain View, CA: International Society of Offshore and Polar Engineers (ISOPE).

[14] C.G. Daley. 2007. Reanalysis of ice pressure-area relationships. Marine Technology, 44(4):234- 244 .

[15] Timothy J.O. Sanderson. 1988. Ice Mechanics and Risks to Offshore Structures. London: Graham \& Trotman.

[16] G.W. Timco and D. Sudom. 2013. Revisiting the sanderson pressure-area curve: Defining parameters that influence ice pressure. Cold Regions Science and Technology 95:53-66.

[17] Robert Frederking. 1999. The local pressure-area relation in ship impact with ice. In Proceedings 15th International Conference on Port and Ocean Engineering under Arctic Conditions, POAC '99. Volume 2, pp 687-696.

[18] C.G. Daley and B.M. Colburne. 2014. Steps2 - a ship structures research program. In Proceedings of the Ship Structure Committee Symposium.

[19] Ian J. Jordaan, Marc A. Maes, Peter W. Brown, and Ivar P. Hermans. 1993. Probabilistic analysis of local ice pressures. Transactions-American Society of Mechanical Engineers. Journal of Offshore Mechanics and Arctic Engineering $115: 83-83$.

[20] Chuanke Li, Ian J. Jordaan, and Rocky S Taylor. 2010. Estimation of local ice pressure using up-crossing rate. Journal of Offshore Mechanics and Arctic Engineering 132(3):031501.

[21] Pentti Kujala and Sankar Arughadhoss. 2012. Statistical analysis of ice crushing pressures on a ship's hull during hull-ice interaction. Cold Regions Science and Technology 70:1-11.

[22] M. Suominen and Pentti Kujala. 2014. Variation in short-term ice-induced load amplitudes on a ship's hull and related probability distributions. Cold Regions Science and Technology 106-107:131-140.

[23] Mark A. Hopkins. 1998. Four stages of pressure ridging. Journal of Geophysical Research: Oceans (1978-2012), 103(C10):21883-21891.

[24] Mark A. Hopkins and Hayley H. Shen. 2001. Simulation of pancake-ice dynamics in a wave field. Annals of Glaciology 33(1):355-360.

[25] Mark A. Hopkins and Alan S. Thorndike. 2006. Floe formation in arctic sea ice. Journal of Geophysical Research: Oceans (1978-2012), 111(C11).

[26] Xiaoshan Lin and T-T Ng. 1997. A three-dimensional discrete element model using arrays of ellipsoids. Geotechnique, 47(2):319-329.

[27] Paul C. Johnson and Roy Jackson. 1987. Frictional-collisional constitutive relations for granular materials, with application to plane shearing. Journal of Fluid Mechanics 176:67-93. 
[28] Damien André, Ivan Iordanoff, Jean-Luc Charles, and Jérôme Néauport. 2012. Discrete element method to simulate continuous material by using the cohesive beam model. Computer Methods in Applied Mechanics and Engineering 213:113-125.

[29] H.A. Carmona, F.K. Wittel, F. Kun, and H.J. Herrmann. 2008. Fragmentation processes in impact of spheres. Physical Review E 77(5):051302.

[30] G.W. Timco and W.F. Weeks. 2010. A review of the engineering properties of sea ice. Cold Regions Science and Technology 60(2):107-129. 


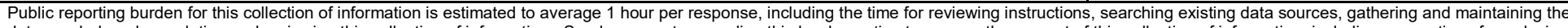

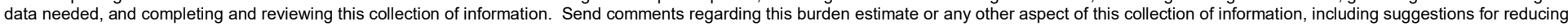

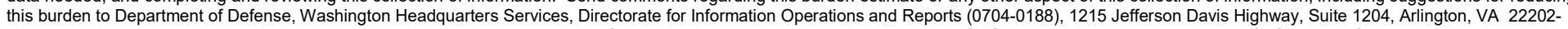

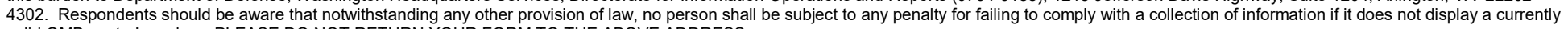
valid OMB control number. PLEASE DO NOT RETURN YOUR FORM TO THE ABOVE ADDRESS.
1. REPORT DATE (DD-MM-YYYY)
September 2018

\section{REPORT TYPE}
Final

\section{TITLE AND SUBTITLE}

3. DATES COVERED (From - To)

5a. CONTRACT NUMBER

Modeling Relevant to Safe Operations of Naval Vessels in Arctic Conditions:

Numerical Modeling of Ice Loads

5b. GRANT NUMBER

5c. PROGRAM ELEMENT NUMBER

6. AUTHOR(S)

Arnold Song, Matthew Parno, Brendan West, and Devin O'Connor

5d. PROJECT NUMBER

5e. TASK NUMBER

MIPR N0001415MP00317

5f. WORK UNIT NUMBER

\section{PERFORMING ORGANIZATION NAME(S) AND ADDRESS(ES)}

8. PERFORMING ORGANIZATION REPORT NUMBER

Cold Regions Research and Engineering Laboratory

U.S. Army Engineer Research and Development Center

ERDC/CRREL SR-18-2

72 Lyme Road

Hanover, NH 03755

9. SPONSORING / MONITORING AGENCY NAME(S) AND ADDRESS(ES)

Office of Naval Research (ONR)

One Liberty Center

875 N. Randolph Street, Suite 1425

Arlington, VA 22203-1995

10. SPONSOR/MONITOR'S ACRONYM(S)

ONR

11. SPONSOR/MONITOR'S REPORT NUMBER(S)

12. DISTRIBUTION / AVAILABILITY STATEMENT

Approved for public release; distribution is unlimited.

\section{SUPPLEMENTARY NOTES}

\section{ABSTRACT}

The Arctic is undergoing profound and rapid change. Diminishing ice in the Arctic will lead to significant changes in the region's activity level as sea routes begin to open and ice conditions become less restrictive. The U.S. Navy may be asked to operate in waters with up to $40 \%$ ice cover.

This work addresses Navy Arctic Roadmap action items to understand the capability, limitations, and operational considerations for successful and safe operation of naval surface vessels in the presence of ice. Current ice impact models were developed for impact scenarios and hull forms more appropriate for Polar Class ships rather than naval hull forms.

The primary unknowns needed to assess operational risks are the magnitude of the pressures that a surface vessel may experience in the case of an ice impact and the structural response to those impact pressures. For this work, we are solely interested in estimating the location and pressures of ice impacts on combatant hull forms. We present an alternative approach that uses the DEM approach to modeling the ice impact problem.

\section{SUBJECT TERMS}

Arctic regions--Sea ice,Arctic regions--Ice floes, Arctic regions--Naval operations, Ice mechanics, Ice navigation, Mathematical models

\begin{tabular}{|c|c|c|c|c|c|}
\hline \multicolumn{3}{|c|}{ 16. SECURITY CLASSIFICATION OF: } & \multirow{2}{*}{$\begin{array}{l}\text { 17. LIMITATION } \\
\text { OF ABSTRACT } \\
\text { UU }\end{array}$} & \multirow{2}{*}{$\begin{array}{l}\text { 18. NUMBER } \\
\text { OF PAGES } \\
44\end{array}$} & \multirow{2}{*}{$\begin{array}{l}\text { 19a. NAME OF RESPONSIBLE PERSON } \\
\begin{array}{l}\text { 19b. TELEPHONE NUMBER } \\
\text { (include area code) }\end{array}\end{array}$} \\
\hline $\begin{array}{l}\text { a. REPORT } \\
\text { Unclassified }\end{array}$ & $\begin{array}{l}\text { b. ABSTRACT } \\
\text { Unclassified }\end{array}$ & $\begin{array}{l}\text { c. THIS PAGE } \\
\text { Unclassified }\end{array}$ & & & \\
\hline
\end{tabular}

